\title{
Orientation vs. Behavior: \\ Gender Differences in Field of Study Choice Set
}

Sigal Alon, Tel Aviv University

Thomas A. DiPrete, Columbia University

September 9, 2013

This research was supported by grants number 200800120 and number 200900169 from the Spencer Foundation, and by Award Number R01EB010584 from the National Institute of Biomedical Imaging and Bioengineering. The content is solely the responsibility of the authors and does not necessarily represent the official views of the Spencer Foundation, the National Institute of Biomedical Imaging and Bioengineering, or the National Institute of Health. Please direct all correspondence to: Sigal Alon, Department of Sociology and Anthropology, Tel Aviv University, Ramat Aviv, Tel Aviv 69978, Israel. [salon1@post.tau.ac.il] 


\begin{abstract}
Women now surpass men in overall rates of college graduation in many industrialized countries, but sex segregation in fields of study persists, even within STEM majors. In a world where gender norms have changed but gender stereotypes remain strong, we argue that attitudes and orientation towards behaviors are less constrained by gendered institutions than are the behaviors themselves. Accordingly, sex segregation in the broader choice set of majors considered by student applicants may be lower than the sex segregation in their first preference field of study selection (first choice). Over time, this may lead to diminishing sex segregation in higher education and the labor market. With unique data on the broader set of fields considered by STEM-bound applicants to elite Israeli universities, we find support for this theory. Moreover, the factors that drive the gender gap in the first choice, in particular labor market earnings, risk aversion and the sex composition of fields, are weaker in the broad set of choices than in the first choice. The result is less segregation in considered majors than in the first choice. We consider the theoretical implications of these results.
\end{abstract}




\section{Orientation vs. Behavior: Gender Differences in Field of Study Choice Set}

Women now surpass men in overall rates of college graduation in many industrialized countries, and women attain masters, professional, and doctoral degrees at rates that approach, equal, and even sometimes exceed men's in some Western countries (Buchmann and DiPrete 2006; Goldin, Katz, and Kuziemko 2006; DiPrete and Buchmann 2013). Despite this progress, however, and despite the near gender parity in math performance (Hyde et al., 2008), sex segregation in fields of study persists at all levels of higher education. Women still pursue science, technology, engineering, and mathematics (STEM) degrees at much lower rates than their male peers do but segregation exist even within STEM majors (Jacobs 1995; Charles and Bradley 2002; England and Li 2006; Mann and DiPrete 2013; Morgan, Gelbgiser and Weeden 2013). This horizontal sex segregation has negative implications for the supply of qualified labor in science and engineering and for the closing of the gender gap in earnings (Dey and Hill 2007), and the question of why this gap persists has become the subject of intense research by a large community of scholars.

Research on the gender gap in field of study has frequently taken a "pathways" approach (e.g., Xie and Shaumann 2003) that focuses attention on the determinants of intent to major in certain fields at various points in the educational life course. The choice model that underlies this approach assumes that students form preferences for majors that are based on a student's fieldspecific aptitudes and perceptions of opportunity in addition to personal taste, self-assessment, and values. Student performance, tastes, values, and perceptions are modeled at the individual 
level as the productions of the home environment, peers, and teachers as well as the broader environment. These environmental influences produce systematic differences between boys and girls in the values, perceptions of opportunity, and perceptions of self-competence via the production of stereotypes and other cultural forces (Eccles et al. 1983, Ridgeway, and Bourg 2004; Ridgeway and Correll. 2004; Steele 1997).

This model for gender differences is informative, but it is limited by its lack of attention to the choice model that is embedded within it. The standard choice model in economics and rational choice-based sociology assumes that decision-makers rank the possible options and choose the one that maximizes utility. From this perspective all options are considered and the "best" one wins. Real people, however, do not process information in this way. It is now well established that people use heuristics when making choices (Tversky and Kahneman 1974; Kahneman 2011). Some options are considered while others are ruled out with only cursory consideration and still others are never thought about in the first place. Individuals do not generally know with precision how important are each of the major components of an alternative to their "utility," and they do not generally have definitive knowledge about how to score each alternative on the relevant dimensions. Instead, they have more or less clear perceptions about the implications of choices, and their perceptions as well as their "utility weights" will change over time in response to (true or false) factual information they learn from their environment about the potential choices, the opinions of significant others, and more subtle environmental cues from the media and elsewhere that may affect the relative attractiveness of alternative options.

We argue that the standard choice model, which is implicitly or explicitly embedded in the study of gender differences in behaviors such as field of study in college, obscures important 
aspects of the process that produces gender differences in behavior in our world of conflict and continuing ambiguity over the salience of gender for educational and career decisions. In a world where gender norms are becoming more egalitarian but where gender stereotypes remain salient (Ridgeway and Correll 2004; Ridgeway 2011; Steele 2010), we conjecture that attitudes and orientations may be less constrained by gendered institutions than are behaviors themselves, especially during periods of cultural change or when conflict between alternative cultural models creates ambiguity for behavior.

Choosing a field of study and a career is an example of an important behavior where cultural models are ambiguous and in conflict—one that pushes for traditional genderdifferentiated behavior, the other for the ideal of gender egalitarianism. Therefore, we expect that gender segregation in the considered options for such behavior, i.e., the broader choice set of considered majors (i.e., orientations) may be lower than are the gender differences in the most preferred major selections (i.e., behavior). ${ }^{1}$ This conjecture is difficult to test because data about the fields of study that are considered by students are almost never available to researchers. Neither "intent to major" or declared major questions in surveys nor administrative data about the college experience allow scholars to observe the student process of ranking and choosing from among candidate fields. In one recent study in economics, students were asked to provide their preference orderings across all majors including their actual major and then are asked their subjective assessments about their abilities or expected earnings in alternative majors (Arcidiacono, Hotz, and Kanga 2012). This study did not focused on gender and used as data "low-stakes" rankings, where the named preferences are "subjective" and do not involve actual behavior with consequences. Zafar (2009) examined the reasons for gender differences in the

\footnotetext{
${ }^{1}$ The student's actual field of study is not necessarily the same as the first choice major (even ignoring the issue of preference change) because entry into fields of study is often competitive.
} 
choice of major at an American university, but he used similar "subjective" data on preference rankings for a sample of college sophomores to examine gender differences in pecuniary and non-pecuniary factors connected with alternative majors. The problem, then, is that the typical data either employ subjective data that does not have behavioral consequences or mixes the outcomes of two decision making processes: the individual (choices) and the institution (admission) — namely, the major that a student is already enrolled in and, consequently, the defacto fit between the student and the major. Hällsten (2010), in contrast, recently used actual behavioral data on major rankings for Sweden (where one can apply to multiple majors but must rank them in the application process), but his focus was on class differences in rankings and the extent to which class effects differed by gender.

In sum, the accumulated evidence on field of study sex segregation is arguably biased because it is largely based on the majors that enrolled students chose and were admitted to, and not on their larger set of preferences. With unusual data on the broader set of fields applied to (including the ranking of choices) in the actual application process by the STEM-bound applicants to elite Israeli universities, the Technion and Tel Aviv University, we study the consideration process behind the formation of major choice sets and the gender gap in making real educational choices.

\section{CONFLICTED PREFERENCES AND THE GENDER GAP IN COLLEGE MAJOR}

The closing and then reversal of the gender gap in rates of college degree attainment was associated with a decline in sex segregation in fields of study during the 1960s through the early 1990s, but in recent years, the trend in sex segregation has stabilized even as the share of college degrees earned by women has continued to grow (Allison and DiPrete 2013). Various theories 
for the persistence of the gender gap have been proposed, but they explain relatively little of the horizontal sex segregation in statistical terms (Xie and Shaumann 2003; Mann and DiPrete 2013). The inability to explain gender segregation satisfactorily in terms of academic skills or work and family values has caused scholars to invoke "gender-essentialism" as the explanation for the divergent pattern for women and men (Charles and Bradley 2009), but this amounts to little more than a renaming of an unexplained phenomenon and has refocused attention on the childhood experiences that may account for the persisting gender gap in STEM fields.

Relatively little is known about the evolution of academic and occupational preferences over the childhood, adolescent, and early adult life course, including not just a person's current preferred option (if one exists) but more generally the set of options that an adolescent considers as she grows older. Two aspects of this process, however, have been addressed in the literature. First, childhood aspirations and evaluations tend to become more realistic as children get older (Ginzberg et al. 1951; Csikszentmihalyi and Schneider 2001; Tracey et al. 2005). Second, gendered stereotypes and gendered preferences emerge early in childhood and continue to elaborate throughout childhood and adolescence (see Legewie and DiPrete 2012 for a recent summary of this literature). Research indicates that parents and educators tend to perceive girls as less qualified than boys in math-oriented fields, which are largely considered masculine, and to view these fields as less important for girls' future career paths than boys' (Correll 2001; Eccles and Jacobs 1986; Eccles, Jacobs, and Harold 1990). These stereotypes are internalized by children and adolescents; for example, most studies of self-assessment of math and science abilities find that girls tend to have lower self-assessments than do boys, and the gap persists even when objective performance in math and science is controlled (Correll 2001, 2004). These 
stereotypes help shape gender identities and they contribute to gender differentiation in academic interests and career choices (Eccles et al. 1983; Ridgeway and Correll 2004; Ridgeway 2011).

Several studies suggest that the relative importance given to intrinsic, altruistic, or social rewards of a job and for the extrinsic rewards of power, money and prestige of a job vary by gender (Hakim 1991; Beutel and Marini 1995, Johnson 2001, Konrad et al. 2000). At least in part, these differences may be traceable to gender differences in the family pay gap and its implications for career choice. Many young women anticipate work-family conflict long before they experience it as a reality in their daily lives (Cinamon 2006). Some women may further perceive the work environments of certain otherwise desirable occupations are unsupportive for women (DiTomaso 1989; Heilman et al. 2004). Boulis and Jacobs (2010), for example, wrote about perceptions by female medical students that they would not feel welcome in certain predominantly medical specialties as being a more important reason for their refrained from entering this specialty than any concerns about such specialties being especially susceptible to work-family climate. Moreover, studies have found evidence that some women perceive the educational environments of predominantly male majors such as engineering as "chilly" and unpleasant for women (Ulku-Steiner et al. 2000; Ecklund, Lincoln, and Tansey 2012).

Perceived conflict between one's gender identity and otherwise attractive academic and career options may affect the extent to which women value career options and may also affect their estimates of their probability of success in fields that lead to these options. These perceptions may in turn produce gender disparities in social and psychological attributes such as risk aversion, confidence, and attitudes toward competition. Laboratory experiments demonstrate that women may be more risk averse and less competitive than men (Bertrand 2010; Croson and Gneezy 2009; Eckel and Grossman 2008; Gneezy, Niederle, and Rustichini 2003; 
Niederle and Vesterlund 2007). For example, Eckel and Grossman (2002) found that men are more likely than women to choose riskier gambles with higher expected payoffs. It appears that while women tend to overestimate the probability of negative outcomes (Flynn, Slovic, and Mertz 1994; Silverman and Kumka 1987; Spigner, Hawkins, and Loren 1993), men are particularly overconfident in their relative abilities when it comes to tasks perceived as masculine (Bertrand 2010). But whether this difference in risk aversion/confidence is an "essentialist" characteristic of gender - even a personality trait that may be related to testosterone levels — or a behavioral preference shaped by cultural beliefs, socialization and environmental factors and thus a response to the gender differences in valuations of career options and estimates of the chances of success is unknown (Bertrand 2010). In this study we develop an explicit measure of risk aversion and model whether and how this construct shapes the major choice set of applicants with the highest quantitative skills. We hypothesize that women applicants are less likely than men to apply to majors in which there is uncertainty regarding their admission likelihood. Our investigation also sheds light on the nature versus nurture debate that surrounds the issue of gender gaps in psychological attributes (see Bertrand (2010) for review of recent literature).

Furthermore, there is evidence that women, relative to men, may systematically underperform in competitive environments and that many women, even among the most able, may simply prefer to stay away from such environments. The core idea in stereotype threat theory is that groups are aware of stereotypes about them, and while they may reject the validity of the stereotypes, they remain vulnerable to anxiety about the possibility that stereotypes are true (Steele and Aronson 1995; Steele 1997). Alon and Gelbgiser (2011), for example, demonstrate that female students thrive in female-dominated learning and social environments. 
Gneezy et al. (2003), meanwhile, report that although women perform as well as men in singlesex settings, men outperform women in more competitive circumstances, where stereotype threat is more likely to be activated. The findings of Gneezy et al. (2003) are especially pertinent to the current study because their subjects are students at the Technion in Israel, the same engineeringand science-oriented university included in our analysis, which suggests that a gender gap in psychological attributes may exist even among STEM-bound applicants with high quantitative skills.

Given that women are more averse to competition than are men (Croson and Gneezy 2009), we expect that women would avoid applying to exceptionally competitive majors relative to their male counterparts, and demonstrate greater aversion to male-dominated fields. We also expect that the labor market returns of a major may shape men's choices more strongly than women's, because jobs with greater levels of risk and competition are paid higher wages (Hartog, Ferrer-i-Carbonell, and Jonker 2002), and because women value the non-pecuniary aspects of jobs — such as security, flexibility in hours, paid leave and vacation provisions - more than they value wages (Currie 1997; Zafar 2009). Indeed, it has been documented that while expected earnings are an essential component in the selection of a college major, women are less influenced by this factor than are men (Montmarquette, Cannings, and Mahseredjian 2002).

In this study we use three objective characteristics to assess how men and women with excellent quantitative skills both rank their alternatives: the expected wage from a job arising from any particular field of study, its sex composition, and the ease or difficulty in being admitted into any particular field of study. The key question, however, is whether women's perception of greater conflict between careers and family formation affects the process of forming preferences and making the choices that lead to the observed difference between men 
and women in their fields of study in college. The standard model would see preferences and choices arise from a weighting of the advantages and disadvantages of each alternative. It would see trends in the distribution of preferences and choices as arising either from changes in the magnitude of advantages and disadvantages or from changes in the way people weight these factors. But this perspective does not tell us whether gender differences in preferences are fully revealed in the distribution of actual choices. It may be that women would alter their career preferences to be more like men's in a world without work-family conflict and without gender bias in work climate. If women imagine a world without gender bias even as they contemplate the world as it is when making educational and career choices, it may be that the alternatives that women and men consider seriously are less colored by gender than are the choices they actually make. Figure 1 diagrams this perspective.

[Figure 1 about here]

We use data that allow us to explore the major choice set, and to examine whether the interplay of two powerful forces — one that pushes for traditional gender-differentiated behavior, the other for a widely accepted (and even more widely acknowledged) ideal of gender egalitarianism - results in greater gender segregation in behavior than in orientation, the considered options for such behavior. Our hypothesis is that attitudes and orientations may be less constrained by gendered institutions than are behaviors themselves. We address the hypothesis with a formal choice model for the formation of the major choice set and how it may contribute to horizontal sex segregation. 


\section{THE CHOICE MODEL: UNIDIMENSIONAL OR MULTINOMIAL?}

The typical rational choice model fit to choice data is a latent index model; individuals assign utilities to each of the possible outcomes, rank the utilities, and choose the highest ranked option. With the notation of Allison and Christakis (1994), individual "i” has utilities

$$
U_{i j}=\mu_{i j}+\varepsilon_{i j}
$$

where " $\mathrm{j}$ " indexes the options from $1, \ldots, \mathrm{J}$. The standard model presumes that $\mu_{i j}$ is a function of alternatives of chooser and of option, i.e.,

$$
\mu_{i j}=\beta_{j} x_{i}+\gamma z_{j}+\theta w_{i j}
$$

where $x_{i}$ are characteristics of choosers, $z_{j}$ are characteristics of the alternatives, and $w_{i j}$ are relations between choosers and alternatives. A single set of coefficients determines the relative preference for any alternative relative to any other alternative. This same set of coefficients determines the probability that any particular option would be the first choice, second choice, or any other ordered choice, given the values of the covariates in equation (1).

If data about the ranking of preferences are available, then this standard framework allows the estimation of a "rank-ordered logit model" (Allison and Christakis 1994), which in the marketing literature is referred to as the "exploded logit model." Using this framework and letting $Y_{i j}$ be the rank of alternative " $\mathrm{j}$ " for individual " $\mathrm{i}$," then the probability that any particular alternative (e.g., alternative $j^{\prime}$ ) is ranked first becomes:

$$
P\left(Y_{i j^{\prime}}=1\right)=\frac{\exp \left(\mu_{i j^{\prime}}\right)}{\left(\sum_{j=1}^{J} \exp \left(\mu_{i j}\right)\right)}
$$

The probability that another alternative $\left(j^{\prime}\right)$ is the second choice becomes

$$
P\left(Y_{i j^{\prime \prime}}=2\right)=\exp \left(\mu_{i j^{\prime \prime}}\right) /\left(\sum_{j \neq j^{\prime}} \exp \left(\mu_{i j}\right)\right)
$$


and so forth for ranks $3, \ldots, \mathrm{J}$. In this model, the ranking of any alternative is determined by the same set of criteria (coefficients) applied to each alternative's specific attributes, and the probability of any particular alternative being chosen first, second, third, or in any other ranked position is similarly governed by a uniform set of criteria. We refer to this model, with its strong assumption about the uniformity of preference determination across the ranking of preference options, as the unidimensional preferences model.

The rank-ordered logit model has frequently been applied in marketing research and very occasionally in sociology. Hällsten (2010) recently used a unidimensional preferences rankordered logit model in order to study class differences in preferences for field of study in Sweden. ${ }^{2}$ We argue, however, that the unidimensional preference model may break down in situations where people use different criteria to decide whether an alternative is near the top of their preferences and whether it is their first choice. In particular, it may break down in distinguishing the criteria that women use to rank a field highly in their preference ordering from the criteria that women use to rank this field as their first choice. What have been called "genderessentialist" forces may have a stronger impact on the first choice than on the considered options, and consequently the level of gender segregation in the considered options may be lower than the segregation revealed in the pattern of first choices. In other words, women's model for their considered options (orientation) may differ from their model for selecting a first choice (behavior).

We examine the validity of the unidimensional preference assumption by studying how gender affects the distinction between strongly considering an alternative and ranking an alternative as one's top choice. We argue that a multinomial preference model, in which

${ }^{2}$ Zafar (2009) and Arcidiacono et al. (2012) also employ the unidimensional preferences model to study the effects of various attributes of majors and expected career outcomes on ranked major preferences; yet they did not have data on actual choices. . 
applicants use different utility weights for the considered majors (orientation) and the top choice (behavior) may be more appropriate to describe the formation of the choice set and horizontal sex segregation. We examine two alternative specifications for this multinomial process that applicant may follow in reality. The first assumes that a sequential decision process in which applicants first determine their top choice, and then determine their top choice from the remaining options. We term this alternative a sequential multinomial preferences model. The second model for the decision making process is what we term a considered options multinomial preferences model. Under this model applicants follow a different logic, in which they first narrow their choices to a top group of options and then decide among this top group. Our analytical strategy tests for the validity of the unidimensional preferences model and then considers the implications of the two alternative multinomial preference models.

\section{THE SETTING}

We test our theory on STEM-bound applicants in elite Israeli universities. The focus on this elite group of applicants with similar academic preparation and orientations helps us circumvent one of the popular explanations for gender disparities in field of study selection, namely the tendency of women to avoid STEM and mathematically-oriented majors in college. The application and admission processes for a bachelor degree at Israeli universities makes them attractive for the current investigation: both the application and admission processes are specific to each combination of major and institution, and departments within each institution vary in their selectivity level; most professional degrees are offered at the undergraduate level; and applicants need to rank their preferences in the application form. The ranking process means that an applicant is considered by every department she applies to and is either accepted or rejected by 
each one. If the applicant is accepted to more than one department, she is informed about the acceptance decision to the department to which she gave the highest preference ranking.

Admission decisions at elite Israeli universities are formulaic, based entirely on a composite score that is calculated by taking the weighted mean of an individual's matriculation diploma grades (weighted by type and level of courses) and psychometric test score (similar to an SAT score). The outcome of the application process depends almost entirely on three variables: the applicant's composite score, the difficulty of gaining admission, and the preference ranking assigned to departments by the applicants. The difficulty of gaining admission depends, of course, on the level of competition, but other factors also matter: universities set constraints on the size of the major based on factors such as the resources needed to teach students in each particular major, absolute standards set by majors for applicant quality, labor market considerations, and the historically-determined factors (such as the capacity of teaching laboratories) that affect each department's ability to handle a class of any given size. Applicants may also apply to departments at other universities, and thus may choose to decline the invitation to matriculate in a specific department at a specific university. It is unfortunately not possible to link applications by the same person to departments at different universities, but this gap does not prevent an analysis of the gender differences in applications to first and second choices within the same university.

\section{Data and Institutions}

To assess the gender differences in field of study choice set, we used the institutional administrative data obtained directly from two Israeli universities for periods ranging from ten to twelve consecutive years (circa 1997 to 2008; for more details see Alon (2011). The first institution is the Technion (TECH), a research university that offers degrees in STEM fields 
only. ${ }^{3}$ To substantiate the Technion results, we replicated the analyses with data from Tel Aviv University (TAU), a comprehensive university that, in addition to STEM fields, offers degrees in the social sciences and the humanities. ${ }^{4}$ To focus on STEM-bound applicants, we limited the TAU analyses to the STEM fields in the applicants' major choice sets. Appendix A details the stages involved in replicating the analyses for TAU.

We analyzed data for applications to the Technion from 1998 to 2008 and to the TAU from 1997 to 2008. Because the specification of the choice model uses lagged variables, we excluded the applicants for the first year for each of these universities from the models. The analyses for the TECH are based on 1,414,822 person-major-choice observations. The analytical sample includes around 27,000 applicants to the Technion over a period of 10 years (1999-2008; we omitted the 1998 applicants), with entries for both first and second choices and complete data for all the relevant variables. The analyses for TAU are based on 771,350 person-major-choice observations, based on data from around 20,000 STEM applicants over a period of 11 years (1998-2008; 1997 applicants were omitted).

The Technion is a highly selective institution. In addition to the typical admission requirements for elite Israeli universities, applicants to the Technion are required to have taken the highest level of math and physics offered in high school. Not surprisingly, as an institution limited to STEM fields, the TECH has a male-dominated student body: only 34 percent of its students from 1998 to 2008 were women, compared to 55 percent in the other three leading universities in Israel. Yet, as Figure 2 depicts, there has been a steady rise in the share of women among TECH applicants, admits, and graduates. In the recent decade, for example, the share of

\footnotetext{
${ }^{3}$ The Technion is sometimes referred to as the Israeli Institute of Technology. In the Shanghai ranking for 2013, it ranked in the $38^{\text {th }}$ place in sciences, in the $46^{\text {th }}$ place in engineering and technology and in $18^{\text {th }}$ place in computer science. Cornell University and the Technion partner in "Cornell Tech" a new applied sciences institution in New York City,

${ }^{4}$ In the Shanghai ranking for 2013 , TAU ranked in the $33^{\text {rd }}$ place in Math, and in $44^{\text {th }}$ place in computer science.
} 
women applicants rose from 34 to 39 percent (1998 and 2008, respectively). At the same time that female applications were increasing, the overall number of applications to the Technion was declining from 6,000 to around 4,500. At TAU the STEM fields are less engineering-oriented than at the Technion and lean more toward the sciences: during the period of investigation, only a third of TAU STEM students were enrolled in engineering fields compared to two thirds at the Technion. Among STEM applicants at TAU, the share of females between 1997 and 2008 was 43 percent (higher than in the Technion), rising from 40 to 45 percent (see Figure 2).

[Figure 2 about here]

In the current investigation, we focus on the major choice set of first-time applicants. When applying to the Technion, applicants can list two ranked preferences for their major (hereinafter referred to as first choice and second choice, respectively), and they cannot choose a dual major. At TAU, applicants may list three ranked preferences for major, each of which may be a dual major. ${ }^{5}$ In order to make the TAU data parallel in structure with the Technion data, we censored the data to only consider a maximum of two STEM choices. We dropped medicine and architecture from the major choice set because these majors can be selected only as a first choice (and are thus excluded from the second choice slot by default), and because their unique admission processes would interfere with the comparison of all applicants on a single scale. Since these are the two most popular STEM majors in women's major choice sets, our results provide conservative estimates for the gender gaps in major choice sets.

During the period of investigation, the Technion offered degrees in 28 fields of study, while TAU offered degrees in 22 STEM fields, and these are the majors we used in our analysis. Tables $1 \mathrm{a}$ and $1 \mathrm{~b}$, respectively, list and characterize these majors by their student bodies. We describe briefly these and other variables used in our analysis in the text below.

${ }^{5}$ More details about the complexity of dual majors are provided in Appendix A 
[Tables $1 \mathrm{a}$ and $1 \mathrm{~b}$ about here]

\section{Individual and Fields of Study Characteristics}

To estimate the ease or difficulty of gaining admission, we used the academic performance information used by the admissions committees of these two universities. An individual's composite academic score is the only criterion for admission used by Israeli universities. It is calculated by taking the weighted mean of an individual's matriculation diploma grades, which are similar to Advanced Placement (AP) grades, and a psychometric test score, which is similar to an SAT score. We use the score calculated by the Technion for all its applicants, and use the engineering composite score calculated by TAU for its applicants to STEM majors. Both scores emphasize applicants' achievements in math and physics courses taken in high school as well as quantitative skills. This variable ranges from 6 to 104 among the Technion applicants, but more than 75 percent of them scored above 80 (mean=83; SD=7). TAU uses a different scale (with a mean of $644(\mathrm{SD}=59)$ ). Figure 3a shows the distribution of the composite academic scores of female and male applicants to the Technion. As can be seen, male scores are slightly higher on average than female scores; the male mean is 83.2 with a standard deviation of 7.5 , and the female mean is 82.6 with a standard deviation of 7.3. At the TAU, a slight academic advantage is also visible (see Figure $3 b$ ). These gender differences are reversed from what is generally found in the population but it is important to keep in mind that these samples are highly selected to favor academically talented students with an interest in science.

[Figures $3 \mathrm{a}$ and $3 \mathrm{~b}$ about here]

The difficulty of gaining admission to a major depends not only on one's own academic score but also on the academic scores of the students one is competing against. To compute academic threshold scores, we gathered information on the academic scores of individual admits 
by major and by year. For each combination of major and year, we calculated the $25^{\text {th }}$ percentile (Q1- bottom quartile), based on the academic scores of admitted students. This variable approximates each major's admission threshold, information that is readily available to applicants. Every year before the application season, the universities in Israel publish these "thresholds" for admission, computed from the academic scores of the previous year's admits. At the Technion, electrical engineering, computer science, and biomedical engineering are the majors with the highest academic threshold, on average (see Table 1a), while chemistry, agricultural engineering, and a program for science teaching are the majors with the lowest. At the TAU, the fields with the highest academic thresholds are bioinformatics, computer engineering and computer science (alone or as part of a joint major with a non-STEM discipline).

During the application process, applicants typically compare their individual academic scores to the previous year's admission thresholds. ${ }^{6}$ This way they can obtain a rough estimate of their likelihood of admission to major $j$. We created a variable that measures the risk involved in the application process to each of the possible majors for each student. This variable is calculated as the distance between an applicant's academic score and the academic threshold for each major based on data from the previous year. A negative value for this variable indicates that the applicant's academic score is below the $25^{\text {th }}$ percentile for major $j$, while a positive value indicates the opposite. ${ }^{7}$ We allow this variable to have nonlinear effects by transforming this difference measure into a set of categorical variables based on the size of the difference. To obtain thresholds for the categorical variables, we used the cut points for the deciles of these difference scores across the distribution of applicants' first and second choices, where the top

\footnotetext{
6 In recent years applicants can compute their composite scores at each institution's website.

${ }^{7}$ For example, a 10-point gap refers to an applicant with an individual academic score of 90 relative to a major academic score of 80 , as well as to an applicant with an individual academic score of 80 relative to a major academic score of 70 .
} 
decile consists of applicants who are least likely to be admitted to a major and the bottom decile consists of applicants who are most likely to be admitted. Table 2 presents the mean gaps for each decile. ${ }^{8}$

On one side of the risk distribution (decile (1)), we observe the largest negative individual-major gaps (-16 points on average at the Technion). This gap suggests that the individuals in this category are underqualified for major $j$, that their likelihood of admission to that major is low, and that applying to major $j$ (as opposed to other majors at the Technion) is the most risky choice for them. At the Technion, the $5^{\text {th }}$ decile contains students with the closest match with the $25^{\text {th }}$ percentile of admits in the previous year for major $j$ and thus serves as the omitted category in the specification (we omitted that category at TAU as well). On the other side of the distribution (decile (10)), we have the largest positive gaps-15 points on average at the Technion — which implies over-qualification, a high likelihood of admission to major $j$, and the least risky application choice. Applicants who apply to majors with more negative gaps are taking bigger risks with their application choice than are students who apply to majors with smaller gaps. Individual differences in risk do not necessarily indicate that one applicant is more risk-averse than the other in the pattern of applications; it may instead be the case that one applicant's preference for highly competitive majors is greater than that of another student. The same observation applies to gender differences in average risk-taking. We return to this issue below.

[Table 2 about here]

\footnotetext{
${ }^{8}$ It should be emphasized that our conception of risk is different from that recently employed by Hällsten (2010) in his study of class differences in field of study choice in Sweden. For Hällsten, applying to a particular field of study is risky if the inequality of earnings for graduates from that field of study is high. For us, applying to a particular field of study is risky if one's chances of being accepted into that program are low.
} 
We also gathered information on the gender of individuals by major and by year and display the average annual share of females in each major's student body. The results for Technion in Table 1a show that the share of women is lowest in mechanical engineering (10 percent), electrical engineering (14 percent; with or without physics), and physics (16 percent). Twelve percent of the student body studied computer science, another male-dominated and lucrative field (77 percent of computer science majors are male). The share of women in industrial and management engineering, however, rises to 41 percent ( 9 percent of the student body), and in chemistry, molecular biochemistry, medical laboratory sciences, and biology exceeds 70 percent. The results for TAU in Table $1 \mathrm{~b}$ depict a similar picture: more than two thirds of the students in biology, chemistry and related fields are female, while they comprise only 16 percent in electrical engineering and in mechanical engineering. Similar to the TECH, 43 percent of students in industrial and management engineering are women. These patterns are similar to what is reported in data for elite universities in the U.S. (e.g., Arcidiacono, Aucejo and Spenner 2012).

To measure labor market expectations, we used a measure for earnings that captures the monthly salary that a graduate in a certain field can anticipate upon labor market entry. The earnings information was obtained from the published reports of the Israeli Central Bureau of Statistics, which are based on the tax authorities' administrative records for on salaried workers, by major and institution. The pay data, based on individual monthly salaries during a graduate's first two years in the labor market, was collected for four cohorts of university graduates (20002003). ${ }^{9}$ Tables $1 \mathrm{a}$ and $1 \mathrm{~b}$ list the expected salaries by field of study. The salaries range from 4,500 to 20,000 New Israeli Shekels (NIS), in 2004 prices. It is immediately evident from Tables

\footnotetext{
${ }^{9}$ The data included the average annual earnings of graduates and the number of months employed. In order to adjust for differences in labor supply, we divided the annual earnings by the number of months employed for graduates in each field of study.
} 
$1 \mathrm{a}$ and $1 \mathrm{~b}$ that the gender gap in field of study choice is associated with labor market earnings. Electrical engineering, for example, is not only one of the largest majors at both institutions, but also the one with the highest expected salary. The least lucrative majors are female-dominated fields. The share of females in a major turns out to be negatively correlated both with the expected salary (-0.66 and -0.84 in the Technion and TAU, respectively) and with the major academic score $(-0.25$ and -0.31 , respectively). Figures $4 \mathrm{a}$ and $4 \mathrm{~b}$ show that the relationship between salaries and the competitiveness of the major is positive at both universities, though clearly this relationship is much stronger at the Technion (with a positive correlation of 0.67 ) than at the TAU (where the correlation is 0.55 ). The symbol for each major in figures $4 \mathrm{a}$ and $4 \mathrm{~b}$ is larger when the percent of majors who are women is larger. It is clearly the case at both universities that the majors which lead to the highest paying jobs tend to be male dominated.

[Figures $4 \mathrm{a}$ and $4 \mathrm{~b}$ about here]

\section{RESULTS}

\section{Horizontal Sex Segregation}

The first step in testing the hypothesis that egalitarian influences are stronger in shaping orientation than in shaping behavior is to assess whether the level of horizontal sex segregation is greater in the broader set of candidate fields than in the first choice. Figure 5 presents the popularity of majors in each institution as revealed by male and female applicants' first choices. About a third of male applicants to the Technion sought admission to electrical engineering (29 percent, including the track with a concentration in physics). The second-most popular major among men was computer science (about 20 percent, including the variant tracks with concentrations in physics and math). Thus, about half of the men listed these two majors as their first choice. A similar trend exists among the TAU applicants: 20 percent of male applicants 
listed electrical engineering as their first choice, and 29 percent listed computer science or computer engineering. An additional 9 percent of male applicants to the Technion, and 6 percent at TAU, listed mechanical engineering as their first choice. While men's distribution of first choices is quite skewed by their strong preference for electrical engineering and computer science, women's first choice distribution is more dispersed. The two most in-demand fields of study among the Technion women are the industrial and management engineering major and the biotech and food engineering major (each of these majors accounts for 13 percent of female applicants). Computer science and biology follow these majors in third and fourth place. The different orientation of the two institutions, engineering vs. sciences, is apparent in the finding that at TAU, almost one in three female STEM-bound applicants listed biology as their first choice.

[Figure 5 about here]

To formally measure the level of horizontal sex segregation in the first choice and to assess whether it is lower in the second choice, as we hypothesize, we calculated three indices of dissimilarity for each of the application cohorts between 1999 and $2008 .{ }^{10}$ We find a high and persistent level of horizontal sex segregation among the applicants to both institutions, even after

\footnotetext{
${ }^{10}$ The results are available upon request. The $\mathrm{D}$ (index of dissimilarity) index, $D=\sum_{j=1}^{J} \mid\left(F_{j} / F\right)-$ $\left(M_{j} / M\right) \mid * 100 * \frac{1}{2}$ which is independent of gender composition but dependent on major composition- that is, the value of D will rise over time if highly segregated majors grow larger and, hence, contribute more to the overall index value (the same will happen if integrated majors become smaller over time) -indicates the percentage of students of one gender who must shift majors in order to generate a sex-natural distribution (Duncan and Duncan 1955). The alternative DS index (Gibbs 1965)

$D S=\sum_{j=1}^{J}\left|\left[\left(\frac{F_{j}}{F_{j}+M_{j}}\right) / \sum_{j=1}^{J}\left(\frac{F_{j}}{F_{j}+M_{j}}\right)\right]-\left[\left(\frac{M_{j}}{F_{j}+M_{j}}\right) / \sum_{j=1}^{J}\left(\frac{M_{j}}{F_{j}+M_{j}}\right)\right]\right| * 100 * \frac{1}{2}$ is independent of major composition but therefore gives equal weight to majors regardless of their size in the construction of the index. Finally, the R index (Charles and Grusky 2004), $A=\exp \left(\frac{1}{J} * \sum_{j=1}^{J}\left\{\ln \left(\frac{F_{j}}{M_{j}}\right)-\left[\frac{1}{J} * \sum_{j=1}^{J} \ln \left(\frac{F_{j}}{M_{j}}\right)\right]\right\}^{2}\right)^{\frac{1}{2}}$ which is independent of both gender and major compositions, is the multiplicative factor by which males and females are, on average, overrepresented in the educational categories being analyzed. Like DS and unlike D, the R index gives equal weight to majors regardless of their relative size.
} 
accounting for majors' size and the influx of women into the applicant pool. Pertinent to the distinction between orientation and behavior is the evidence that in almost all years of the investigation, the level of sex segregation in the first choice majors is higher than in the second choice majors.

\section{The Formation of the Choice Set}

We address the hypothesis that women's model for their considered options (orientation) may differ from their model for selecting a first choice (behavior) with a formal choice model. We begin with the unidimensional preference model — with its strong assumption about the uniformity of preference determination across the ranking of preference options - as a baseline. In this analysis we assumed that men and women both rank their alternatives based on two characteristics: the expected wage from a job arising from any particular field of study, and the ease or difficulty in being admitted into any particular field of study. ${ }^{11}$ Table 3 shows the estimated coefficients of this model for men and women, with panel A coefficients being for the Technion and panel B for the TAU. Figure 6 graphs the predicted probabilities of choosing each major, based on these coefficients, and also the residuals from the models in panel A of Table 3 for the Technion, and panel B for the TAU.

[Table 3 about here]

[Figure 6 about here]

There is a big gender gap at both universities in the responsiveness of applicants to the economic potential of majors. For men, higher expected returns translates into a higher probability of applying to that major, net of the distance between that major's threshold and

\footnotetext{
${ }^{11}$ In the case of a single choice being to do a dual STEM major, which is an allowed possibility at the TAU, we use the characteristics in each sub-choice.
} 
one's own composite academic score: every extra 1000 NIS per month boosts the odds by 25 percent that a male applying to the Technion will apply to this major. In contrast, expected earnings have no effect at all on a woman's likelihood of applying to a major. At TAU, the male responsiveness to expected labor market earnings is smaller than at the Technion but the gender gap at TAU is nearly as large as at the Technion because female applicants to majors at TAU are actually less likely to apply to any particular major if the labor market returns to this major are relatively large. Because the major options at the two universities are different, we cannot attribute differences in the coefficients to special characteristics of either the applicants or the school. The important point for our analysis is the fact that the gender gap in responsiveness to potential earnings is similar at both schools, and in the expected direction.

Next we turn to the gender profiles of risk behavior displayed by applicants at the two universities. At least from the perspective of these baseline models (we will turn to more elaborate models shortly), TAU and the Technion differ in the gender profile of risk behavior. As Table 3, panel B shows, women and men at TAU have generally similar risk profiles. $^{12}$ In contrast, female applicants at the Technion appear to be unambiguously less risk-averse than men in their application decisions (see Table 3, panel A). The modal decile for female applicants is category 4, which is risker than the category 5 modal category for males; this difference is especially notable in light of the slightly lower mean academic scores for women than for men. ${ }^{13}$ Moreover, female students are relatively more likely to apply to majors in high risk deciles than are males, and they are also less likely to apply to majors for which they are "overqualified" than are males.

\footnotetext{
${ }^{12}$ Women are less likely than men to apply to majors in the riskiest deciles, but the differences between the genders are not large.

${ }^{13}$ A "category 4 major" is thus defined with respect to a specific student; these categories measure relative distance between students and potential majors.
} 
The gender difference in the coefficient pattern has obvious and important implications for the predicted gender difference in the pattern of applications. Figure 6 shows the predicted probabilities of men and women applying to each of the majors at the Technion. As implied by the coefficient pattern, the baseline model predicts a variance in application patterns across majors for males but not for females. Table 1a shows that the majors with the highest earnings potentials are generally the ones that are most popular, and this relationship is approximately reproduced in Figure 6, but only for the males. Expected wages and the difficulty of admission provide little guidance as to the majors favored by the women applicants to the Technion. In contrast, the baseline results for the TAU do provide some predictive power for female as well as male applicants because of the negative coefficient on labor market wages in the female model; across the spectrum of majors at the TAU, women are generally more likely to apply to those fields that pay less, while men apply to the fields that pay more.

Panels A and B of Table 3 suggest that female applicants are either less risk averse than are male applicants (at the Technion) or not much more risk averse (at the TAU), but these results are not necessarily informative about the true gender differences in risk aversion. An individual student may apply to highly competitive majors because she is risk-loving, but she may instead simply prefer for other reasons the majors that are highly competitive. Similarly, men may appear more risk-averse than women only because their average preferences for majors differ on other grounds than risk from those of women. We can better isolate the impact of risk on the pattern of applying to majors by including fixed effects for the different major possibilities in the models for each university. A fixed effects model will show whether year-toyear fluctuations in the difficulty of getting into specific majors affect the pattern of applications that year differently for men and women. This model, therefore, will provide a clearer measure 
of how male and female applicants respond to changes in risk, which, as we noted above, the applicants are generally aware of. Panels C and D of Table 3 display the coefficients for risk in the fixed effects model for both universities. ${ }^{14}$ Both panels show that female applicants are apparently more risk-averse than male applicants, once the underlying differences in the gender pattern of major preferences is controlled. ${ }^{15}$ Net of the baseline "essentialist" gender pattern of major preferences, female applicant odds of applying to a major in the highest risk category at the Technion were only 68 percent as high (relative to the middle category) as for males, and female odds of applying to the second highest risk category were only 77 percent those of males. ${ }^{16}$ The gender difference at the TAU was smaller, but women applicants had lower (91 percent) odds of applying to the highest risk category than males, and 93 percent as likely as males to apply to the second highest risk category, after the "essentialist" aspects of the major choices were controlled.

All the results discussed to this point, however, make the strong assumption that the unidimensional preferences model is correct both as the basis for determining the set of considered options and for determining the final choice. This assumption is empirically testable. As discussed above, our theoretically preferred model is a multinomial preferences model in which applicants use different utility weights in their first choice than they do in their second choice. We test for the validity of the unidimensional preferences model in model 2 by suppressing information about the second choice from the data and estimating a conditional logit model; this is equivalent to a rank-order logit model (equation (1)) when only the top choice is ranked in the data.

\footnotetext{
${ }^{14}$ Expected wages do not vary over time in our data so the coefficient for expected wages cannot be estimated in a fixed effects model.

${ }^{15}$ The hypothesis of gender equality of the risk coefficients is rejected quite strongly $\left(\mathrm{X}^{2}=39\right.$ with 9 df for the Technion).

${ }^{16}$ These results are obtained from estimates of a model that interacts gender with risk.
} 
Table 4 shows the set of coefficients that correspond to Table 3 except that they pertain to the first choice only. The results reveal that women applicants are less responsive to the wage expectations of majors and that women are more risk averse than men when picking a major as a top choice, once the underlying "essentialist" preference structure for majors is controlled. The important question for us is whether the unidimensional preferences model accurately captures the full process of considering, ranking, and the first choice major. We report statistical (Hausman) tests for the unidimensional preferences model in Appendix B, and clearly reject the null hypothesis that the rankings of majors by Technion and TAU applicants follows the unidimensional preferences model for male applicants only, for women applicants only, and for the two genders combined. The process of deciding one's first choice and one's second choice major cannot accurately be described as a simple matter of ranking majors on their characteristics using a single set of utility weights for either women or men.

[Table 4 about here]

Clearly, the results from Tables 3 and 4 reject the unidimensional preferences model. We fit a model for the second choice major, given that the applicant had already made a first choice. This step estimates the weights of factors that determine an applicant's second choice, and allow us to contrast the decision process separately for second choices and for first choices. Table 5 shows the set of coefficients in the second choice model. Two findings are evident from the comparison of the coefficients in Table 5 to those in the first choice model (Table 4). The first finding is that women and men differ in the importance of expected wages when deciding on their second choice, just as was true for their first choice. Women applicants to the Technion pay no attention to expected wages for either their first or their second choice major, while male applicants to the Technion weight expected wages about equally for both choices. At the TAU, 
the coefficient for expected wages on second choice major is negative for women applicants, as it is for their first choice application, while for male applicants the weight for expected wages is positive. The second finding is that both women and men are more risk averse in their second choice application than in their first, but the shift towards risk aversion is much larger for male than for female applicants. Women applicants to the Technion continue to be more risk averse than men in their second choice major, but the gender difference is much smaller for the second choice than for the first choice. Women applicants at the TAU are actually less risk averse in their second major choice than are men, which is a turnaround from the much greater risk aversion shown by female relative to male TAU applicants for the first choice major. To put it another way, men are considerably more willing than women to apply to risky majors for their first choice than are women at both the Technion and the TAU, while for the second choice the men are as much or more focused on risk as are the women.

[Table 5 about here]

The substantive interpretation of this pattern is straightforward. The most competitive majors are the ones that pay the highest average salaries. The applicants who focus on salaries when making their decisions about majors are predominantly males. Male applicants who care predominantly about salaries are therefore often in a position of being only marginally competitive or worse for their preferred major unless they have top academic scores. The model results imply that males often use their first choice to apply to a "reach" major and protect themselves in their second choice with a safer major. Female applicants, who have a similar overall distribution of academic scores as the male applicants, are less focused on the most lucrative majors than are the males. Women applicants are consequently less likely than men to be in a situation where they are strongly motivated by financial goals to apply to the majors that 
are hardest to get into and thus would be "reach" majors for them. What is less clear, however, is the reason for the gendered pattern. It could be that Israeli women are truly less interested in labor market returns than are men and thus their pattern of major preferences is "undistorted" by market considerations. It is instead possible that female applicants are deterred from applying to the most competitive majors because women are more risk-averse, and therefore that the gender difference in risk-aversion contributes to the different pattern of applications by males and females. A third possibility is that female applicants are deterred from applying to the most competitive majors because these majors are male dominated and uncomfortable for women, and the deterrence produced by this discomfort is the reason for the "essentialist" difference in the baseline distribution of majors applied to by males and females (we next assess this possibility). The time-varying pattern of risk-avoidance suggests that females are indeed more risk averse on average than males, but the data are nonetheless open to multiple interpretations of why women and men end up in a different distribution of majors.

The strategy just described assumes a sequential decision process in which applicants first determine their top choice, and then determine their second choice from the remaining options (a sequential multinomial preferences model). Applicants in reality may indeed follow such a sequential process when making their choices. An alternative conceptualization, however, is that applicants make a different sequential decision in which the first step is to narrow their choices to a set of considered options and the second step is to decide which of the considered options is the first choice (a considered options multinomial preferences model). Table 6 shows the coefficients on the risk variables that stem from this conceptualization. Panel A gives the coefficients for the decision model about the considered option set, and Panel B gives the coefficients for the decision about which of the considered options is the first choice. 
Panel A shows, as before, that women applicants are more risk averse than men; women avoid putting a major in risk deciles 1, 2, and 3 into their considered option set even after the baseline “essentialist" preferences are controlled. Panel B reinforces the pattern of gender differences in Panel A in showing that men more than women favor riskier majors when choosing which of their considered options should be the first choice. With the data at hand we cannot adjudicate between the sequential multinomial preference process and the considered options multinomial preference process, but what is clear is that under both models applicants are more likely to take a risk for their top choice than for the second choice and men take more risks than women.

[Table 6 about here]

We next test the possibility that the sex composition of fields (and occupations) is an important criterion in shaping women choices and the hypothesis that second choices are less gender-segregated than are first choices. We perform this test in three ways. First, we use the predicted major choices for the applicants from a model with dummy variables for each major to compute the index of dissimilarity for the first choices and for the second choices as well as from the unidimensional preferences model and the considered options model, and we compare these values directly. Second, we include a one-year lagged value for each major's sex composition of the majors, and we compare the coefficient of sex composition for the unidimensional preferences model and for the multinomial preference model. Third, we determine whether the sex composition of the major is related to the choice of which major in the considered options set is the first choice, net of the effect of sex composition on the construction of the considered options set. The results from these tests are displayed in Table 7.

[Table 7 about here] 
The first column of Table 7 shows the index of dissimilarity of the distribution of predicted majors under alternative models for the major choice process at both institutions. Each of these indices is a function of the coefficient for lagged percent female in the column 2. The table clearly shows that first choice majors at the Technion are more gender segregated $(\mathrm{D}=$ .434 ) than are second choice majors ( $\mathrm{D}=.367$ ), and that this difference is statistically significant. ${ }^{17}$ A difference of .434 and .367 is large enough to be of substantive importance; it equals the change in the index of dissimilarity measure for gender segregation of occupations in the U.S. labor force between 1980 and 2000 (Blau et al. 2012), or the overall change in gender segregation in fields of study for BA recipients in the U.S. between the late 1980s and the present (Mann and DiPrete 2013). The second panel of Table 6 shows comparable results for TAU. The results for TAU are not as dramatic as for the Technion but the same general pattern prevails. Gender segregation in first choice majors is considerably greater than for second choice majors, just as was true at the Technion

One might argue that the lower level of segregation visible in predicted second choice options relative to first choice options is driven not by differences between a female applicant's orientation and behavior but rather by changes in male behavior that is connected with strategic behavior in major application. According to this interpretation, males prefer male-dominated high-paying hard to get into majors, and they use more gender-integrated majors as second choice backups to their often more high risk first choice for majors. While there is certainly some truth to this interpretation it is not the whole story. Partly this is because women's risk preferences also differ significantly between their first and second choice, even if the difference

\footnotetext{
${ }^{17}$ The difference between the coefficients on gender composition in these two models is 0.01 , which is about 10 times as large as the square root of the sum of the squared standard errors for these two estimates.
} 
in this regard for women is not as large as for men. ${ }^{18}$ Importantly for our theory, women's first and second choices differ in their response to the gender composition of majors. To show this, we next focus only on the female applicants, and analyze the implications of the percent female in a major on a woman's choice patterns. The second column in each panel of Table 7 shows that the impact of the percent female of a major on a female applicant's major choice is stronger on her first choice major than on her second choice major. At the Technion, every one percentage point increase in the sex composition of a major increases a woman's odds of applying to that major as her first choice by 2.6 percent, but only increases her odds of applying to the major as a second choice by 1.6 percent A qualitatively similar though less pronounced pattern is also visible at the TAU.

The fourth entry in the second column of each panel in Table 7 shows that the process of developing a considered options set is also strongly associated with gender composition of the alternative majors. The odds that a major will be included in a woman's considered options set rises by 2.1 percent for each one percentage point increase in that major's percent female at the Technion, and by 1.2 percent at the TAU. It could certainly have been the case that women gave strong weight to a potential major's gender composition in deciding whether to include it as a finalist in her choice but that she made her first choice decision from her two finalist options on other grounds. However, the data support the interpretation that the gender composition of a major plays a continuing role even after a female applicant has whittled down her top choice decision to only two contenders. At the Technion, each percentage point increase in the percent female of a "finalist" major raises the odds that it will emerge as a woman's top choice by nearly a full percentage point at the Technion and by 0.38 of a percent at the TAU. Thus, under either

\footnotetext{
${ }^{18}$ The Hausman test results (Appendix B) show statistical significance tests in the difference between coefficients from the alternative models. Moreover, the differences in risk coefficients across the unidimensional and multinomial models are significant.
} 
the sequential multinomial preference model or the considered options multinomial preference model, women applicants are more likely for her top choice than for her backup choice to choose a major that is disproportionately female. The world of second choices is less gendered than is the world of first choices. Similarly, the world of considered options is less gendered than is the world of first choices.

\section{DISCUSSION}

The conclusion from our investigation is that orientation is less constrained by traditional forces than behavior, and that, as a result, sex segregation in the broader choice set of considered majors is lower than in the first choice selections. We show that the factors that drive the gender gap in the first choice, in particular labor market earnings, risk aversion and the sex composition of fields, are weaker in the broad set of choices than in the first choice. Men tone down their willingness to take risks in their second major backup plan. Women, meanwhile, tone down their preference to be in a major that is disproportionately female for their second choice. The result is less segregation in the world of second choices than in the world of first choices.

The evidence that the gender gap in risk orientation disappears in the second-choice selection of major leads to a radical conclusion: in making educational choices, the gender gap in risk aversion, competitiveness and confidence is situational. That is, in a high stakes, first choice situation, women are less likely than men to take chances. These findings suggest that risk aversion is a behavioral preference and point to the role of the perceived importance of a situation in determining its level and in shaping the difference between women and men. Our results do not rule out the possibility of biological grounds for the gender gap in risk aversion, but they do suggest that innate differences, if they indeed exist, are moderated by environmental forces. 
The definitive interpretation of this moderating tendency in second choices, however, cannot be ascertained from the data themselves. We see three different interpretations of the meaning of this gender difference. It may be the case that men are more confident than women and more inclined to compete in the application process for the most competitive majors. It may instead be the case that men are more focused on external rewards, that their focus has produced a positive correlation between competitiveness and expected salaries, and that women are less interested in competing for these majors because they are less interested in external rewards than are men. A third possibility is that women are repelled by male dominated majors and it is the male domination of these majors rather than women's lack of interest in external rewards that affects their preferences. The results from the multinomial preferences model go a long way towards clarifying the different choice processes undertaken by women and men. Additional research with different data is needed to clarify the questions that cannot be answered with data on academic records, preference orderings, competitiveness of majors and expected salaries by graduates in the various majors.

Another question that cannot be answered with the existing data is whether change is occurring in the considered option sets of academically elite Israeli women and whether the changes in the considered options set is more rapid than are the changes in the top choice major. The period of time covered by these data is one of relatively weak trends in the gendered character of major preferences. In this way, the Israeli data are similar to data for the U.S. (Mann and DiPrete 2013), where trends are also weak. Nonetheless, when change picks up again or when more years of data are available in this world of slow change, we predict that the additional data will show that change comes more quickly to the considered options set than it does to the final choice itself. If true, such a finding would also imply that behavioral change is 
a multi-part process in which people first take an option seriously and then more seriously before they finally begin to behave in ways that reveal their shifting orientations. More data are needed in order to establish the validity of our prediction as well as to understand how the barriers between attitudes and behavior erode over time. 


\section{REFERENCES}

Alon, Sigal. 2011. "The Diversity Dividends of a Need-Blind and Color-Blind Affirmative Action Policy". Social Science Research 40(6):1494-1505.

Alon, Sigal and Dafna Gelbgiser. 2011. "The Female Advantage in College Academic Achievements and Horizontal Sex Segregation." Social Science Research 40(1):107-119.

Arcidiacono, Peter V., Joseph Hotz and Songman Kang. 2012. "Modeling College Major Choices Using Elicited Measures of Expectations and Counterfactuals." Journal of Econometrics 166:3-16.

Arcidiacono, Peter, Esteban M. Aucejo, and Ken Spenner. 2012. "What Happens After Enrollment? An Analysis of the Time Path of Racial Differences in GPA and Major Choice." IZA Journal of Labor Economics 1:5.

Bertrand, Marianne. 2010. "New Perspectives on Gender." Pp. 1545-1592 in Handbook of Labor Economics 4b, edited by O. Ashenfelter and D. Card. New York: Elsevier.

Blau, Francine D., Peter Brummund, and Albert Yung-Hsu Liu. 2012. "Trends in Occupational Segregation by Gender 1970-2009: Adjusting for the Impact of Changes in the Occupational Coding System.” Demography 50:471-492.

Buchmann, Claudia and Thomas A. DiPrete. 2006. "The Growing Female Advantage in College Completion: The Role of Family Background and Academic Achievement." American Sociological Review 71(4):515-541.

Boulis, A. K, and J. A Jacobs. The Changing Face of Medicine: Women Doctors and the Evolution of Health Care in America. Ithaca: Cornell University Press, 2010.

Charles, Maria and Karen Bradley. 2002. "Equal But Separate? A Cross-National Study of Sex Segregation in Higher Education." American Sociological Review 67(4):573-599.

Charles, M., and K. Bradley. 2009. Indulging our Gendered Selves? Sex Segregation by Field of Study in 44 Countries. American Journal of Sociology 114: 924-76.

Charles, Maria and David B. Grusky. 2007. "Egalitarianism and Gender Inequality." Pp. 327-342 in Inequality: Contemporary and Foundational Readings in Race, Class, and Gender edited by D. Grusky and S. Szelenyi. Boulder, CO: Westview Press.

Charles, Maria and David B. Grusky. 2004. Occupational Ghettos: The Worldwide Segregation of Women and Men. Stranford, California: Stanford University Press.

Cinamon, Rachel Gali. 2006. “Anticipated Work-Family Conflict: Effects of Gender, SelfEfficacy, and Family Background.” The Career Development Quarterly 54: 202-215. 
Correll, Shelley J. 2001. "Gender and the Career Choice Process: The Role of Biased SelfAssessments." American Journal of Sociology 106(6):1691-1730.

Correll, Shelley J. 2004. "Constraints into Preferences: Gender, Status, and Emerging Career Aspirations." American Sociological Review 69(1):93-113.

Croson, Rachel and Uri Gneezy. 2009. "Gender Differences in Preferences." Journal of Economic Literature 47(2):1-27.

Csikszentmihalyi, Mihaly and Barbara Schneider. 2001. Becoming Adult: How Teenagers Prepare For The World Of Work. Basic Books.

Currie, Janet. 1997. "Gender Gaps in Benefits Coverage." Pp. 175-198 in The Handbook of Human Resource Management, edited by D. Lewin, D. Mitchell and M. Zaidi. Greenwich CT: JAI Press.

Dey, Judy Goldberg, and Catherine Hill. 2007. Behind the Pay Gap. Washington, DC: AAUW Educational Foundation,

DiPrete, Thomas A. and Claudia Buchmann. 2013. The Rise of Women: The Growing Gender Gap in Education and What it Means for American Schools. New York: Russell Sage Foundation.

DiTomaso, Nancy. 1989. " Sexuality in the workplace: Discrimination and harassment." Pp. 7190 in The Sexuality of Organization, edited by Jeff Hearn, Deborah L. Sheppard, Peta Tancred-Sheriff, and Gibson Burrell. 1989. US: Sage Publications.

Duncan, Otis D. and Beverly Duncan. 1955. "A Methodological Analysis of Segregation Indexes." American Sociological Review 20(2):210-217.

Duxbury, L.E. and C.A. Higgins. 1991. "Gender differences in work-family conflict." Journal of Applied Psychology 76:60-74.

Eccles, J.S., T.F. Adler, R. Futterman, S.B. Goff, C.M. Kaczala, J.L. Meece, and C. Midgley. 1983. "Expectancies, values, and academic behaviors." In Achievement and Achievement Motivation, edited by J.T. Spence, pp. 75-146. W.H. Freeman.

Eccles, Jacquelynne S. and Janis E. Jacobs. 1986. "Social Forces Shape Math Attitudes and Performance." Signs: Journal of Women in Culture and Society 11(2):367-380.

Eccles, Jacquelynne S., Janis E. Jacobs and Rena D. Harold. 1990. "Gender role stereotypes, expectancy effects, and parents' socialization of gender differences." Journal of Social Issues 46(2):183-201. 
Eckel, Catherine C. and Philip J. Grossman. 2008. "Men, Women and Risk Aversion: Experimental Evidence." Pp. 1061-1073 in Handbook of Experimental Economics Results 1, edited by C. Plott and V. Smith. New York: Elsevier.

------. 2002. "Sex differences and statistical stereotyping in attitudes towardfinancial risk." Evolution and Human Behavior 23(4):281-295.

Ecklund, Elaine Howard, Anne E. Lincoln and Cassandra Tansey. 2012. "Gender Segregation in Elite Academic Science." Gender \& Society 26: 693-717.

England, Paula and Su Li. 2006. "Desegregation stalled: the changing gender composition of college majors, 1971-2002." Gender \& Society 20(5):657-677.

Flynn, James, Paul Slovic and C. K. Mertz. 1994. "Gender, Race, and Perception of Environmental Health Risks." Risk Analysis 14(6):1101-1108.

Gerber, T.P., and S.Y. Cheung. 2008. "Horizontal Stratification in Postsecondary Education: Forms, Explanations, and Implications.” Annual Review of Sociology 34: 299-318.

Gibbs, Jack P. 1965. "Occupational Differentiation of Negroes and Whites in the United States." Social Forces 44(2):159-165.

Ginzberg, Eli, Sol W. Ginsburg, Sidney Axelrad, and Herma John L. 1951. Occupational Choice. New York: Columbia University Press.

Gneezy, Uri, Muriel Niederle and Aldo Rustichini. 2003. "Performance in competitive environments: gender differences." Quarterly Journal of Economics 118:1049-1074.

Hartog, Joop, Ada Ferrer-i-Carbonell and Nicole Jonker. 2002. "Linking Measured Risk Aversion to Individual Characteristics." Kyklos 55(1):3-26.

Hyde, J. S., S. M. Lindberg, M. C. Linn, A. B. Ellis, and C. C. Williams. 2008. "Gender Similarities Characterize Math Performance." Science 321:494-495.

Jacobs, Jerry A. 1996. "Gender Inequality and Higher Education." Annual Review of Sociology 22:153-185.

------ 1995. "Gender and Academic Specialties: Trends among Recipients of College Degrees in the 1980s." Sociology of Education 68(2):81-98.

Hakim, C. 1991. “Grateful Slaves and Self-made Women: Fact and Fantasy in Women's Work Orientations." European Sociological Review 7: 101-121.

Hällsten, Martin. 2010. "The Structure of Educational Decision Making and Consequences for Inequality: A Swedish Test Case." American Journal of Sociology 116: 806-54. 
Heilman, M.E., Wallen, A.S., Fuchs, D. \& Tamkins, M.M. (2004). Penalties for success: Reactions to women who succeed at male tasks. Journal of Applied Psychology, 89, 416427.

Kahneman, Daniel. 2011. Thinking, Fast and Slow. New York: Macmillan

Legewie, Joscha and DiPrete, Thomas A., High School Environments, STEM Orientations, and the Gender Gap in Science and Engineering Degrees (February 21, 2012). Available at SSRN: http://ssrn.com/abstract=2008733 or http://dx.doi.org/10.2139/ssrn.2008733

McFadden, Daniel. 1974. "Conditional Logit Analysis of Qualitative Choice Behavior." Pp. 105-142 in Frontiers in Econometrics., edited by P. Zarembka. New York: Academic Press.

Mann, Allison, and Thomas DiPrete. 2013. "Trends in Gender Segregation in the Choice of Science and Engineering Majors." Social Science Research 42: 1519-1541.

Montmarquette, Claude, Kathy Cannings and Sophie Mahseredjian. 2002. "How Do Young People Choose College Majors?" Economics of Education Review 21(6):543-556.

Morgan, Stephen L., Dafna Gelbgiser, and Kim A. Weeden. 2013. "Feeding the Pipeline: Gender, Occupational Plans, and College Major Selection.” Social Science Research 42: 989-1005.

Niederle, Muriel and Lise Vesterlund. 2007. "Do Women Shy Away from Competition? Do Men Compete Too Much?" Quarterly Journal of Economics 122(3):1067-1101.

Reynolds, John R. and Stephanie W. Burge. 2008. "Educational Expectations and The Rise in Women's Post-secondary Attainments." Social science research 37(2):485-499.

Ridgeway, Cecilia L. 2011. Framed by Gender: How Gender Inequality Persists in the Modern World. New York: Oxford University Press.

Ridgeway, C. L. and C. Bourg. 2004. "Gender as status: An expectation states theory approach.” In The Psychology of Gender, edited by H. Alice, Anne E. Beall, and Robert J. Sternberg, pp. 217-241. New York: Guilford Press.

Ridgeway, Cecilia L. and Shelley J. Correll. 2004. "Unpacking the Gender System: A Theoretical Perspective on Gender Beliefs and Social Relations." Gender and Society 18:510-531.

Silverman, Jane M. and Donald S. Kumka. 1987. "Gender Differences in Attitudes Toward Nuclear War and Disarmament." Sex Roles 16:189-203.

Spigner, Clarence, Wesley E. Hawkins and Wendy Loren. 1993. "Gender Differences in Perception of Risk Associated with Alcohol and Drug Use among College Students." Women and Health 20(1):87-97. 
Steele, Claude. 2010. Whistling Vivaldi: And Other Clues to How Stereotypes Affect Us. New York: WW Norton \& Company.

Steele, CM. 1997. "A threat in the air: How stereotypes shape intellectual identity and performance." The American Psychologist 52:613-629.

Steele, CM and J. Aronson. 1995. "Stereotype threat and the intellectual test performance of African Americans." Journal of Personality and Social Psychology 69:797-811.

Tracey, Terence J.G., Steven B. Robbins, and Christy D. Hofsess. 2005. "Stability and change in interests: A longitudinal study of adolescents from grades 8 through 12." Journal of Vocational Behavior 66:1-25.

Turner, Sarah E. and William G. Bowen. 1999. "Choice of Major: The Changing (Unchanging) Gender Gap." Industrial and Labor Relations Review 52(2):289-313.

Tversky, Amos, and Daniel Kahneman. 1974. "Judgment Under Uncertainty: Heuristics and Biases.” Science 185: 4157: 1124-1131.

Ulku-Steiner, B., B. Kurtz-Costes and C.R. Kinlaw. 2000. "Doctoral Student Experiences in Gender-Balanced and Male-Dominated Graduate Programs." Journal of Educational Psychology. 92; 296-307.

Wai, J., M. Cacchio, M. Putallaz, and M. C. Makel. 2010. Sex Differences In The Right Tail Of Cognitive Abilities: A 30-Year Examination. Intelligence 38(4):412-423.

Williams, J. 2000. Unbending Gender: Why Family and Work Conflict and What to Do About It. Oxford: Oxford University Press.

Wilson, Kenneth L. and Janet P. Boldizar. 1990. "Gender Segregation in Higher Education: Effects of Aspirations, Mathematics Achievement, and Income." Sociology of Education 63(1):62-74.

Xie, Yu and Kimberle A. Shauman. 2003. Women in Science: Career Processes and Outcomes. Cambridge, MA: Harvard University Press.

Zafar, Basit. 2009. "College major choice and the gender gap." FRB of New York Staff Reports, no. 364. 


\section{Appendix A: TAU Data and Sample}

This appendix details the steps required to replicate the Technion analyses for TAU. In order to focus on STEM-bound applicants, we limit the analyses to the STEM fields in applicants' major choice sets. STEM applicants are defined as applicants who chose at least one STEM major for their first or second choice. When applying to TAU, applicants may list three ranked preferences for major, each of which may be a dual major (although this is not an option for several of the STEM majors). To deal with this complexity, we devised a twofold strategy: In cases where one of the majors in a dual major selection is non-STEM, we ignored the information for the non-STEM major and considered it an entry with missing data. In cases where both majors in a dual major were STEM, we allowed for multiple choices. Each of the two STEM majors was regarded as a sub-choice, with distinct characteristics (such as individualmajor match, sex composition and wage). For example, if the applicant's first choice was a biology-chemistry dual major, we derived two sub-choices from it (biology and chemistry), using the applicant's personal data (identical for both sub-choices) and each sub-choice's distinct characteristics. Instead of using the general composite academic score, used in TAU for all applicants, we used the academic composite engineering score used by TAU to rank applicants for STEM fields. This score places greater weight on quantitative skills and on math and physics courses completed in high school than does the general composite academic score. 
Figure 1: The Formation of the Major Choice Set

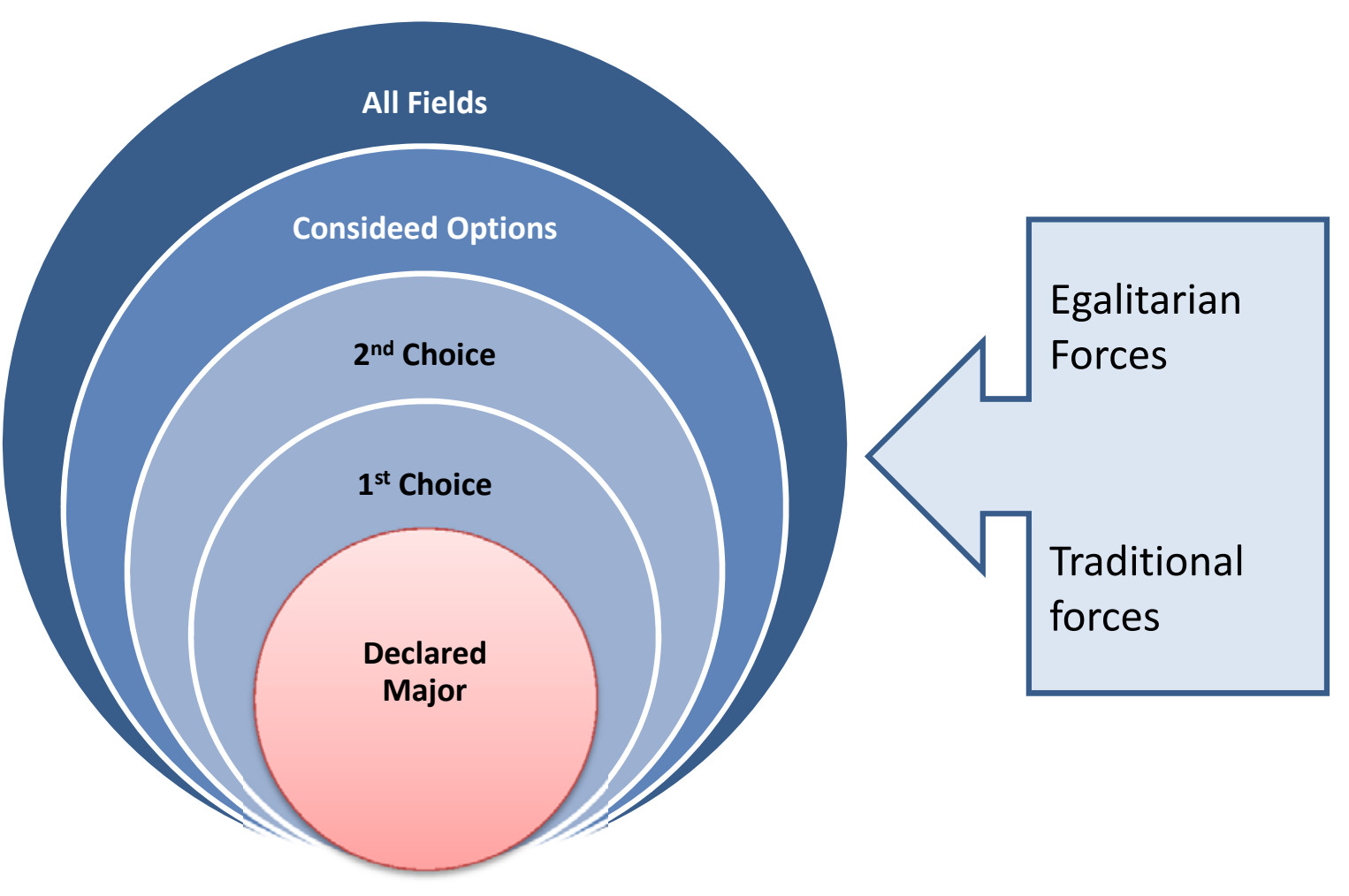


Figure 2: The share of women in the applicant, admit, and student bodies
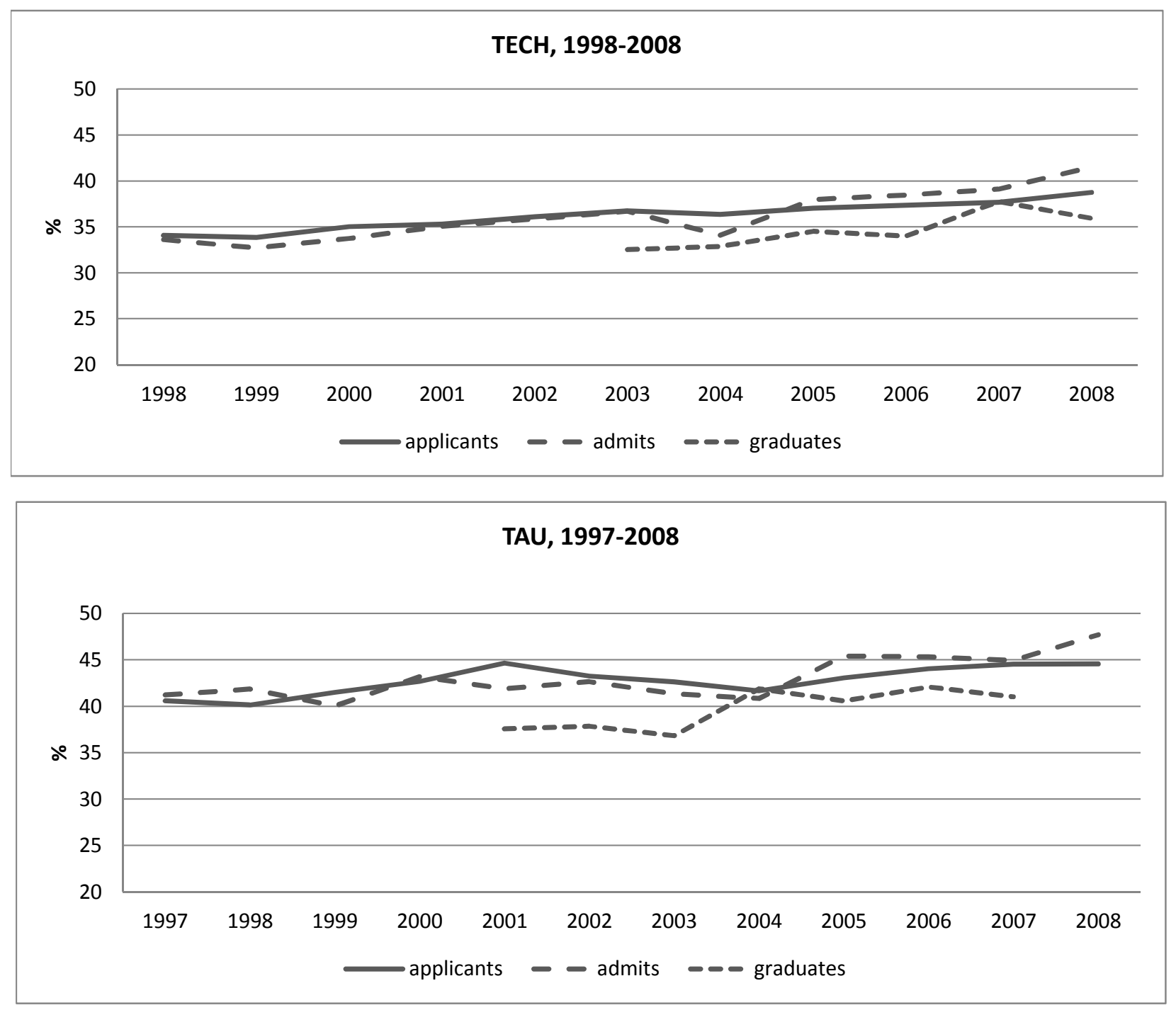
Figure 3a. Distribution of Academic Scores, by Gender, TECH

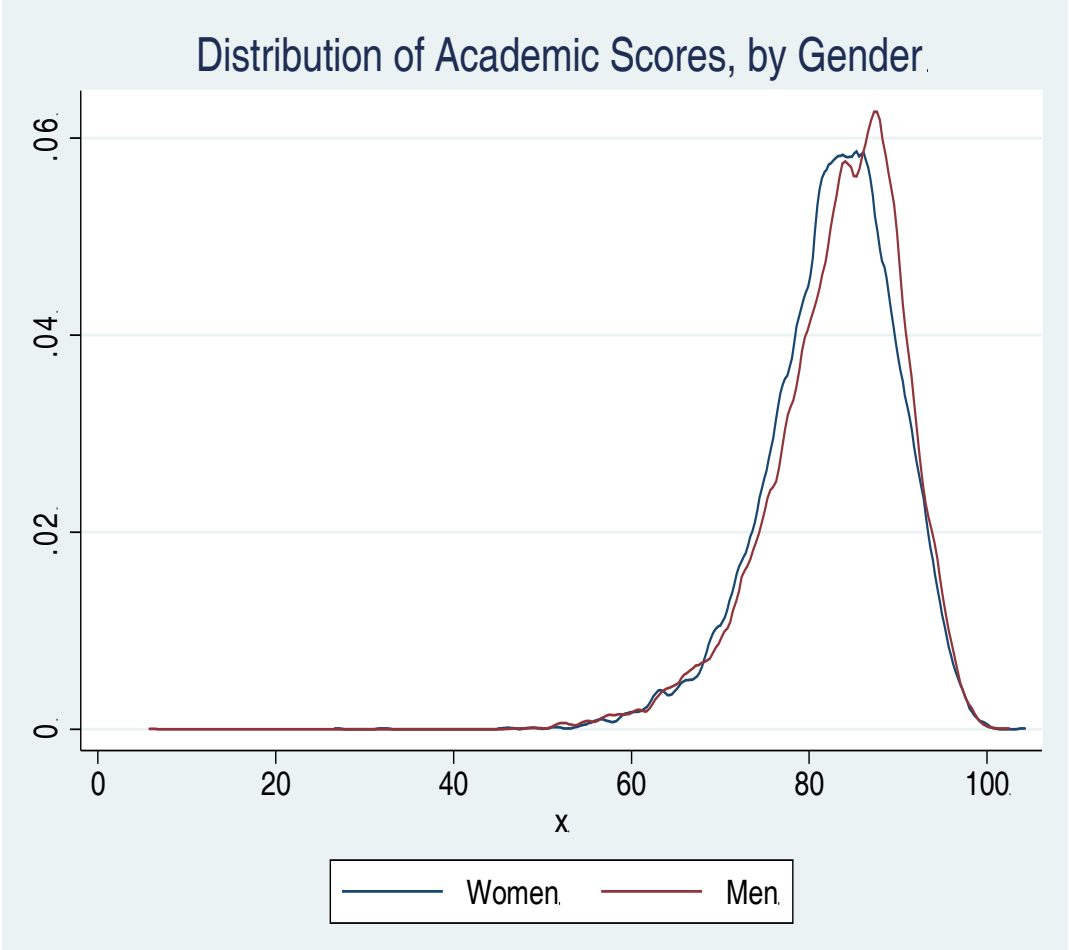

Figure 3b. Distribution of Academic Scores by Gender, TAU

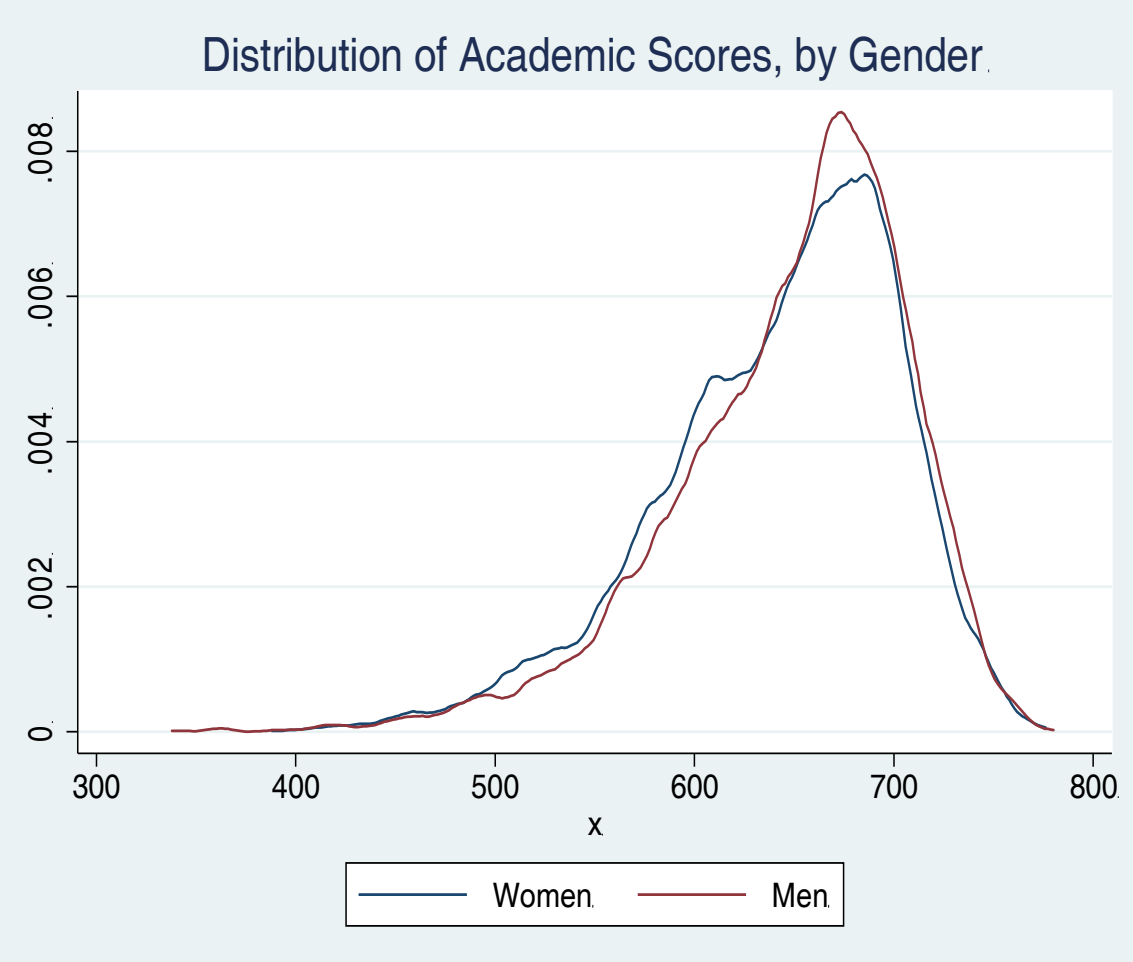


Figure 4: The relationship between major's salary, competitiveness, and the share of females
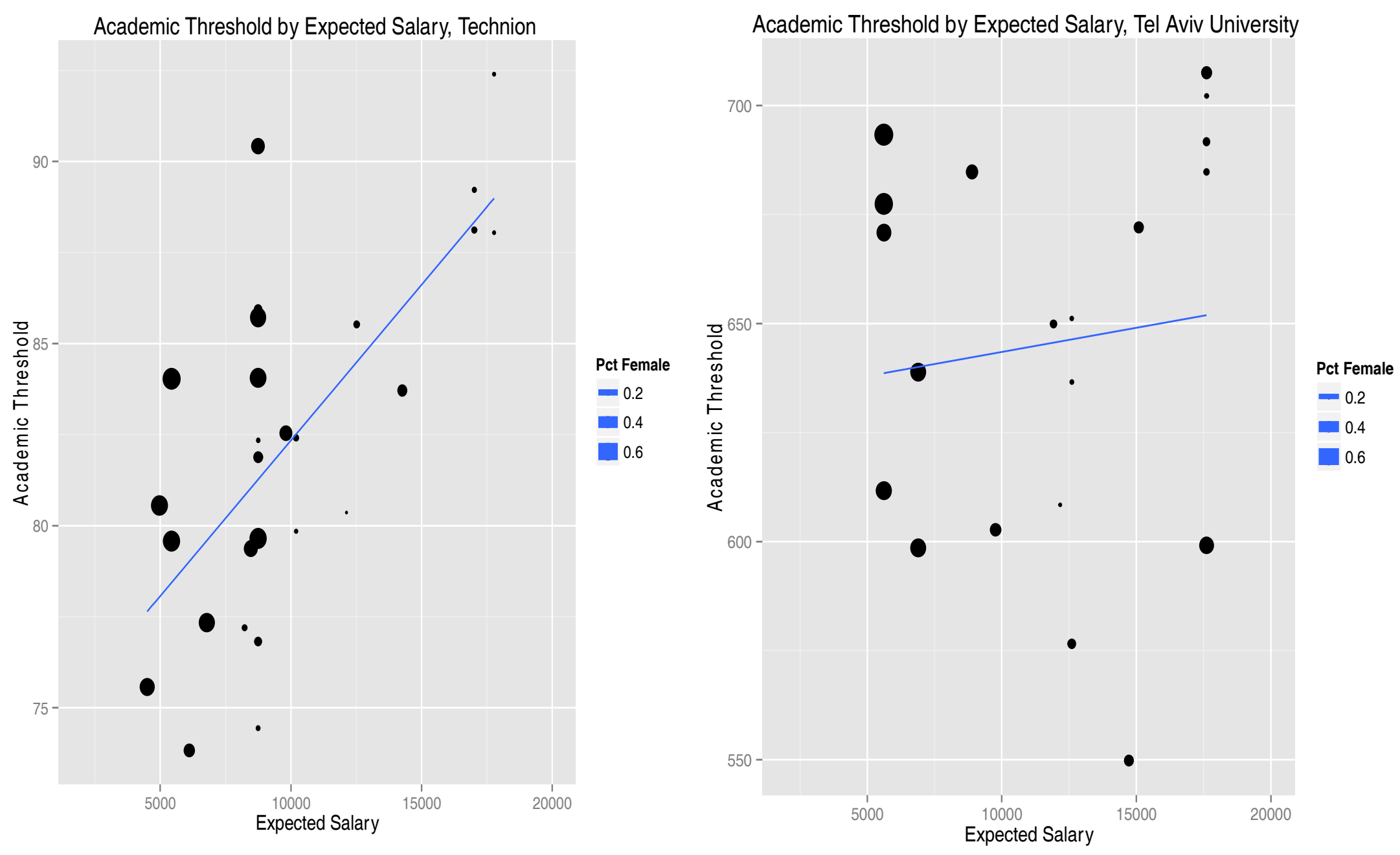
Figure 5: The distribution of first choice majors, by gender

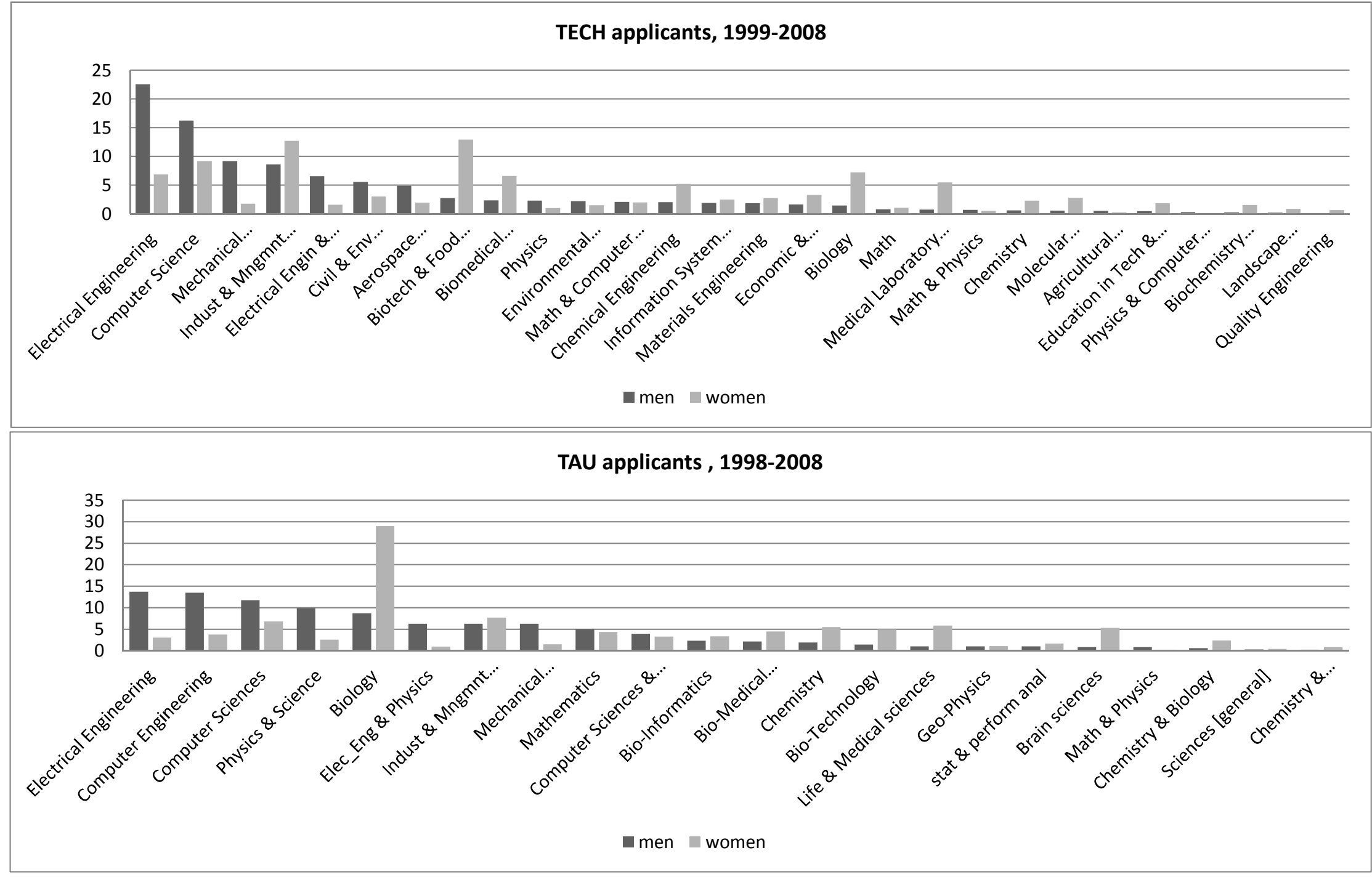


Figure 6a1. Predicted Field of Study for the Technion from a Rank-Ordered Logit Model (Table 3) with Risk and Wages as Covariates, TECH Figure 6a2. Residuals from the Rank-Ordered Logit Model of Panel A, Table 3
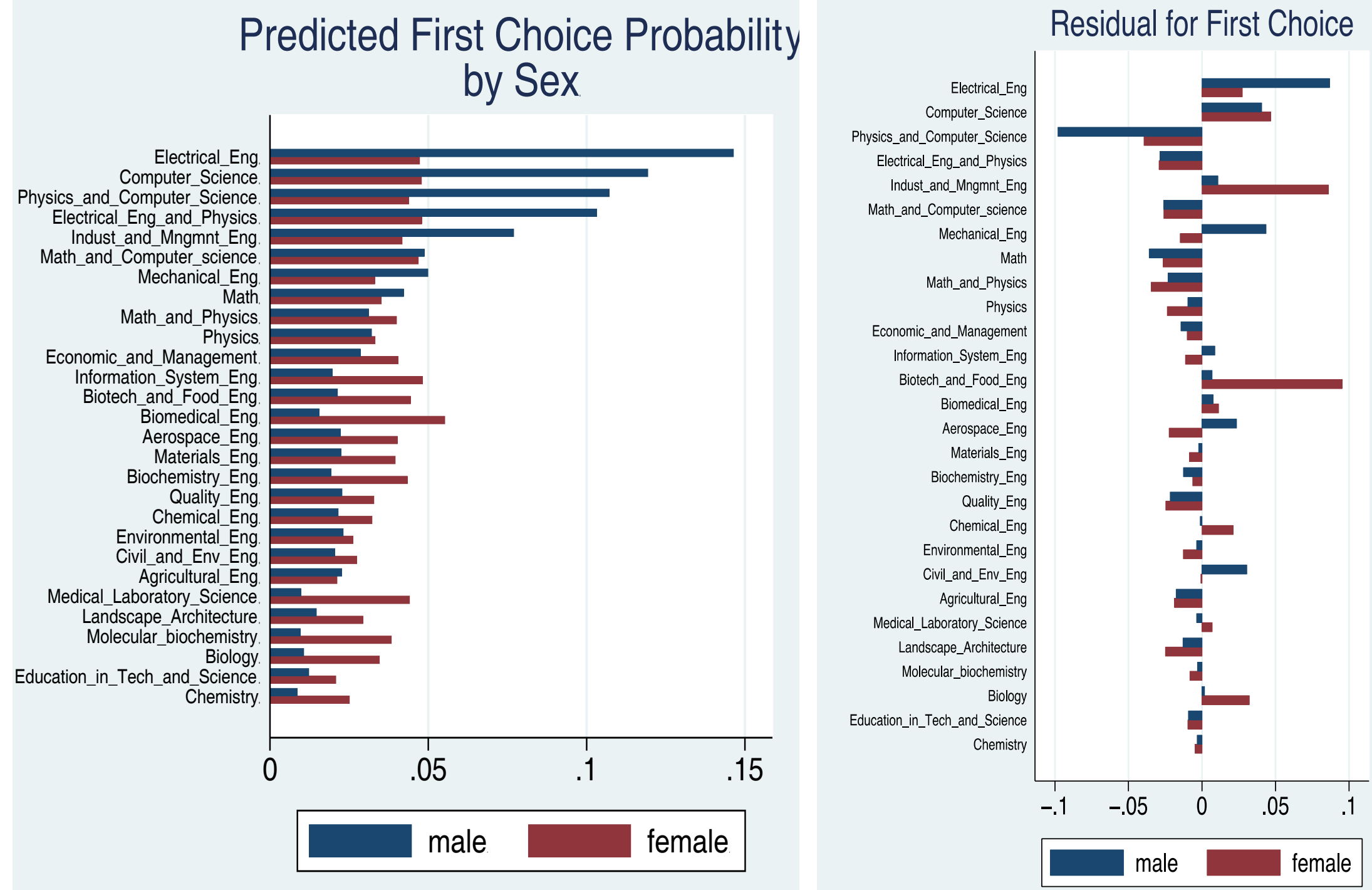
Figure 6b1. Predicted Field of Study for the Technion from a Rank-Ordered Logit Model (Table 3) with Risk and Wages as Covariates, TAU Figure 6b2. Residuals from the Rank-Ordered Logit Model of Panel B, Table 3
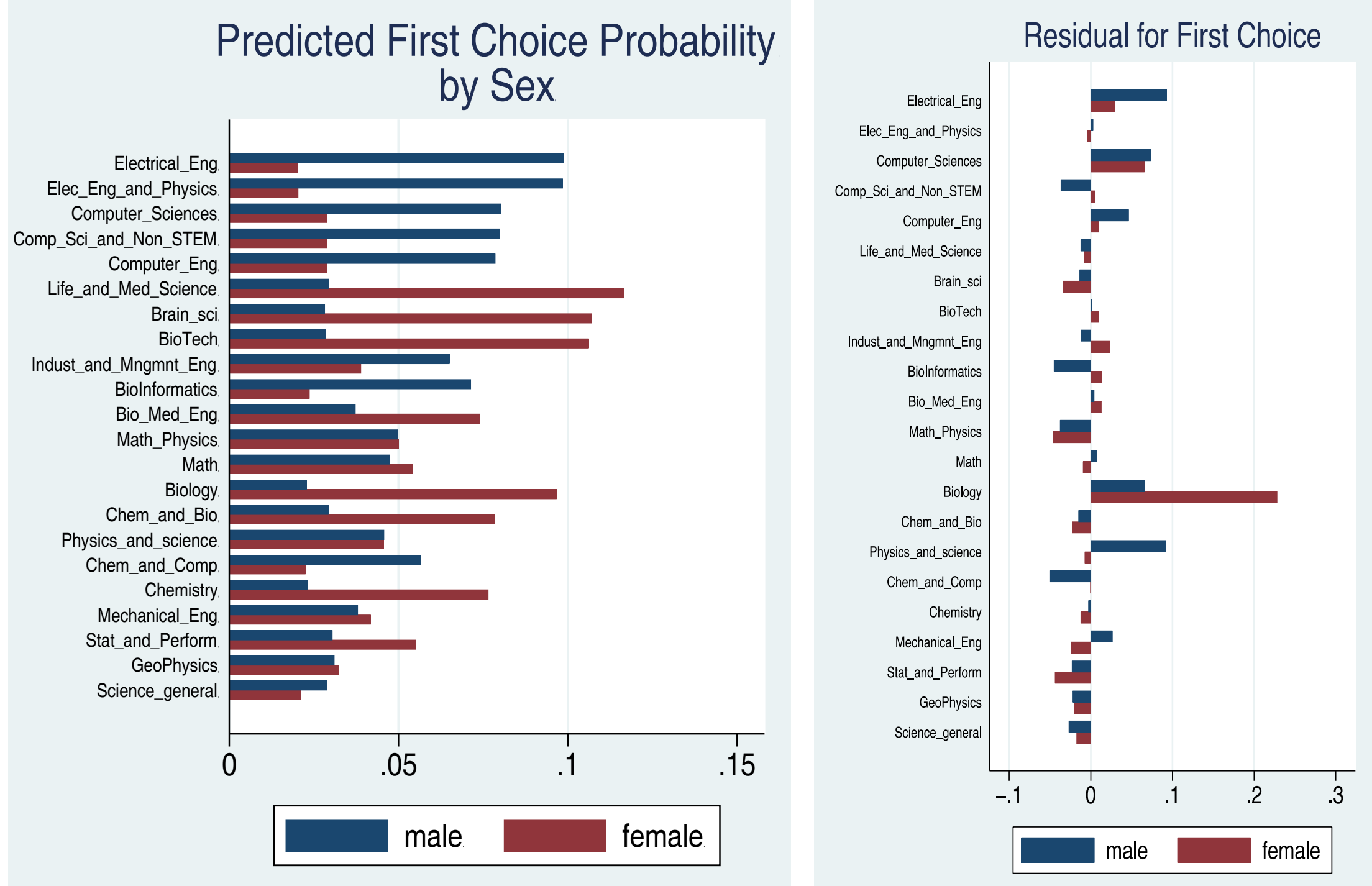


\begin{tabular}{|c|c|c|c|c|c|}
\hline Major \# & Major & $\begin{array}{l}\text { Share of } \\
\text { students }\end{array}$ & $\begin{array}{l}\text { \% Women } \\
\text { (students) }\end{array}$ & $\begin{array}{c}\text { Academic } \\
\text { threshold } \\
\text { (P25 admits) }\end{array}$ & $\begin{array}{c}\text { Expected } \\
\text { monthly } \\
\text { salary (NIS) }\end{array}$ \\
\hline 3 & Electrical_Eng & $14.5 \%$ & $14 \%$ & 88 & 17777 \\
\hline 12 & Computer_Science & $10.7 \%$ & $23 \%$ & 88 & 17019 \\
\hline 8 & Indust_and_Mngmnt_Eng & $9.9 \%$ & $41 \%$ & 84 & 14262 \\
\hline 2 & Mechānical_Eng & $9.3 \%$ & $10 \%$ & 80 & 12128 \\
\hline 1 & Civil_and_Env_Eng & $7.2 \%$ & $23 \%$ & 77 & 8223 \\
\hline 7 & Aerospace_Eng & $4.1 \%$ & $17 \%$ & 82 & 8745 \\
\hline 5 & Biotech_and_Food_Eng & $3.7 \%$ & $70 \%$ & 84 & 8745 \\
\hline 15 & Education_in_Tech_and_Science & $3.6 \%$ & $47 \%$ & 74 & 6113 \\
\hline 4 & Chemical_Eng & $3.5 \%$ & $58 \%$ & 79 & 8464 \\
\hline 10 & Physics & $3.3 \%$ & $15 \%$ & 80 & 10199 \\
\hline 19 & Environmental_Eng & $3.2 \%$ & $32 \%$ & 77 & 8745 \\
\hline 17 & Biology & $3.1 \%$ & $73 \%$ & 80 & 5430 \\
\hline 21 & Materials_Eng & $2.5 \%$ & $41 \%$ & 82 & 8745 \\
\hline 24 & Electrical_Eng_and_Physics & $2.5 \%$ & $15 \%$ & 92 & 17777 \\
\hline 25 & Biomedical_Eng & $2.3 \%$ & $57 \%$ & 90 & 8745 \\
\hline 26 & Information_System_Eng & $2.0 \%$ & $35 \%$ & 86 & 8745 \\
\hline 18 & Math_and_Computer_science & $1.9 \%$ & $26 \%$ & 86 & 12518 \\
\hline 6 & Agricultural_Eng & $1.9 \%$ & $18 \%$ & 74 & 8745 \\
\hline 16 & Chemistry & $1.8 \%$ & $63 \%$ & 76 & 4502 \\
\hline 9 & Math & $1.7 \%$ & $35 \%$ & 81 & 1141 \\
\hline 11 & Economic_and_Management & $1.6 \%$ & $54 \%$ & 83 & 9812 \\
\hline 20 & Molecular_biochemistry & $1.6 \%$ & $72 \%$ & 81 & 4966 \\
\hline 13 & Landscape_Architecture & $1.0 \%$ & $68 \%$ & 77 & 6782 \\
\hline 14 & Medical_Laboratory_Science & $0.9 \%$ & $76 \%$ & 84 & 5430 \\
\hline 23 & Math_and_Physics & $0.8 \%$ & $24 \%$ & 82 & 10199 \\
\hline 27 & Biochemistry_Eng & $0.7 \%$ & $69 \%$ & 86 & 8745 \\
\hline 22 & Quality_Eng & $0.6 \%$ & $73 \%$ & 80 & 8745 \\
\hline 28 & Physics_and_Computer_Science & $0.1 \%$ & $20 \%$ & 89 & 17019 \\
\hline
\end{tabular}

1) Biomedical Engineering started in 1999; System Engineering in 2001;

Biochemistry Engineering in 2004; and Physics \& Computer Science in 2005

2) based on averages of graduates between 2000-2003

Note : sorted by the share of students 


\begin{tabular}{|c|c|c|c|c|c|}
\hline Major \# & Major & $\begin{array}{l}\text { Share of } \\
\text { students }\end{array}$ & $\begin{array}{c}\text { \% Women } \\
\text { (admits) }\end{array}$ & $\begin{array}{c}\text { Academic } \\
\text { threshold } \\
\text { (P25 admits) }\end{array}$ & $\begin{array}{c}\text { Expected } \\
\text { monthly } \\
\text { salary (NIS) }\end{array}$ \\
\hline 7 & Biology & $16.2 \%$ & $67 \%$ & 612 & 5615 \\
\hline 9 & Electrical_Eng & $9.9 \%$ & $16 \%$ & 672 & 20296 \\
\hline 5 & Math & $9.3 \%$ & $31 \%$ & 650 & 11920 \\
\hline 6 & Computer_Sciences & $9.1 \%$ & $27 \%$ & 685 & 17608 \\
\hline 11 & Mechanical_Eng & $6.6 \%$ & $17 \%$ & 608 & 12169 \\
\hline 3 & Chemistry & $5.8 \%$ & $67 \%$ & 599 & 6893 \\
\hline 2 & Physics_and_science & $5.7 \%$ & $21 \%$ & 637 & 12598 \\
\hline 8 & Indust_and_Mngmnt_Eng & $5.4 \%$ & $43 \%$ & 672 & 15091 \\
\hline 22 & Comp_Sci_and_Non_STEM & $4.5 \%$ & $32 \%$ & 692 & 17608 \\
\hline 13 & Bio_Med_Eng & $3.8 \%$ & $52 \%$ & 685 & 8892 \\
\hline 10 & Computer_Eng & $3.8 \%$ & $21 \%$ & 702 & 17608 \\
\hline 4 & Stat_and_Perform & $3.0 \%$ & $48 \%$ & 603 & 9766 \\
\hline 18 & Elec_Eng_and_Physics & $2.7 \%$ & $13 \%$ & 691 & 20296 \\
\hline 19 & GeoPhysics & $2.2 \%$ & $37 \%$ & 577 & 12598 \\
\hline 20 & Biolnformatics & $1.8 \%$ & $46 \%$ & 708 & 17608 \\
\hline 16 & Chem_and_Bio & $1.8 \%$ & $66 \%$ & 639 & 6893 \\
\hline 12 & Life_and_Med_Science & $1.7 \%$ & $77 \%$ & 677 & 5615 \\
\hline 17 & BioTech & $1.6 \%$ & $62 \%$ & 671 & 5615 \\
\hline 14 & Math_Physics & $1.5 \%$ & $20 \%$ & 651 & 12598 \\
\hline 15 & Chem_and_Comp & $1.4 \%$ & $61 \%$ & 599 & 17608 \\
\hline 21 & Brain_sci & $1.2 \%$ & $78 \%$ & 693 & 5615 \\
\hline 1 & Science_general & $0.9 \%$ & $42 \%$ & 550 & 14725 \\
\hline
\end{tabular}

1) Life_and_Med_Science started in 2000; Bio_Med_Eng in 2001; Biolnformatics in 2001;

Brain sci in 2002; BioTech in 2002; Chem and Bio in 2006;

Chem_and_Comp terminated in 2007 ; Science_general in 2006

2) based on averages of graduates between 2000-2003

Note : sorted by the share of students 
Table 2: The mean score for the individual-major match by deciles ${ }^{1}$

\begin{tabular}{ccc}
\hline \hline decile & TECH & TAU \\
\hline 1 & -15.87 & -143.39 \\
2 & -7.7 & -80.03 \\
3 & -4.06 & -49.9 \\
4 & -1.39 & -27.78 \\
5 & 0.89 & -9.39 \\
6 & 3.04 & 7.83 \\
7 & 5.22 & 26.14 \\
8 & 7.54 & 47.96 \\
9 & 10.37 & 75.47 \\
10 & 15.33 & 121.55 \\
\hline
\end{tabular}

1) This is calculated as the distance between the applicant's academic score and the major's academic treshold (P25) in the previous year.

category 1 indicates ind. below major's threshold - most risky application choice category 10 indicates ind. above major's threshold - least risky application choice "Perfect match": category 5 
Table 3. Effects of expected wage and Difficulty of Being Accepted, by Gender on the Ranked Choice

\begin{tabular}{|c|c|c|c|c|c|c|c|c|}
\hline \multirow[b]{4}{*}{ VARIABLE } & \multicolumn{2}{|c|}{$\begin{array}{l}\text { PANEL A } \\
\text { TECH }\end{array}$} & \multicolumn{2}{|c|}{$\begin{array}{l}\text { PANEL B } \\
\text { TAU }\end{array}$} & \multicolumn{2}{|c|}{$\begin{array}{l}\text { PANEL C } \\
\text { TECH }\end{array}$} & \multicolumn{2}{|c|}{$\begin{array}{l}\text { PANEL D } \\
\text { TAU }\end{array}$} \\
\hline & & & & $M$ & $\mathrm{~F}$ & & $\mathrm{~F}$ & M \\
\hline & \multicolumn{4}{|c|}{ without controlling for major dummy variables } & \multicolumn{4}{|c|}{ controlling for major dummy variables } \\
\hline & $(1)$ & $(2)$ & $(3)$ & $(4)$ & $(5)$ & $(6)$ & $(7)$ & $(8)$ \\
\hline 1bn.cb_pct & $\begin{array}{c}-1.287^{* * *} \\
(0.0525)\end{array}$ & $\begin{array}{l}-2.655^{\star * *} \\
(0.0376)\end{array}$ & $\begin{array}{l}-1.064^{* * *} \\
(0.0534)\end{array}$ & $\begin{array}{c}-1.015^{\star * *} \\
(0.0380)\end{array}$ & $\begin{array}{c}-1.654^{* * *} \\
(0.0779)\end{array}$ & $\begin{array}{c}-1.274^{\star * *} \\
(0.0531)\end{array}$ & $\begin{array}{c}-0.989 * * * \\
(0.0884)\end{array}$ & $\begin{array}{c}-0.891^{* * *} \\
(0.0609)\end{array}$ \\
\hline 2.cb_pctl & $\begin{array}{c}-0.806^{\star * *} \\
(0.0372)\end{array}$ & $\begin{array}{c}-1.547^{* * *} \\
(0.0257)\end{array}$ & $\begin{array}{l}-0.707^{* * *} \\
(0.0418)\end{array}$ & $\begin{array}{l}-0.676^{* * *} \\
(0.0301)\end{array}$ & $\begin{array}{c}-1.018^{* * *} \\
(0.0499)\end{array}$ & $\begin{array}{l}-0.763^{* * *} \\
(0.0341)\end{array}$ & $\begin{array}{l}-0.625^{\star * *} \\
(0.0594)\end{array}$ & $\begin{array}{l}-0.551^{* * *} \\
(0.0413)\end{array}$ \\
\hline 3.cb_pctl & $\begin{array}{c}-0.382^{* * *} \\
(0.0309)\end{array}$ & $\begin{array}{l}-0.838^{* * *} \\
(0.0212)\end{array}$ & $\begin{array}{l}-0.345^{\star * *} \\
(0.0367)\end{array}$ & $\begin{array}{l}-0.392^{* * *} \\
(0.0263)\end{array}$ & $\begin{array}{c}-0.495^{\star * *} \\
(0.0365)\end{array}$ & $\begin{array}{c}-0.351^{* * *} \\
(0.0253)\end{array}$ & $\begin{array}{l}-0.310^{* * *} \\
(0.0450)\end{array}$ & $\begin{array}{l}-0.299^{* * *} \\
(0.0311)\end{array}$ \\
\hline 4.cb_pctl & $\begin{array}{l}0.0498^{*} \\
(0.0267)\end{array}$ & $\begin{array}{l}-0.159^{* * *} \\
(0.0185)\end{array}$ & $\begin{array}{l}-0.150^{* * *} \\
(0.0345)\end{array}$ & $\begin{array}{l}-0.214^{* * *} \\
(0.0241)\end{array}$ & $\begin{array}{l}0.00245 \\
(0.0283)\end{array}$ & $\begin{array}{c}0.0836^{* * *} \\
(0.0199)\end{array}$ & $\begin{array}{l}-0.131^{* * *} \\
(0.0373)\end{array}$ & $\begin{array}{l}-0.153^{* * *} \\
(0.0256)\end{array}$ \\
\hline 6.cb_pctl & $\begin{array}{l}-0.410^{* * *} \\
(0.0288)\end{array}$ & $\begin{array}{l}-0.188^{* * *} \\
(0.0200)\end{array}$ & $\begin{array}{l}-0.126^{\star * *} \\
(0.0334)\end{array}$ & $\begin{array}{l}-0.101^{* * *} \\
(0.0231)\end{array}$ & $\begin{array}{l}-0.389^{\star * *} \\
(0.0303)\end{array}$ & $\begin{array}{l}-0.423^{* * *} \\
(0.0213)\end{array}$ & $\begin{array}{l}-0.151^{* * *} \\
(0.0358)\end{array}$ & $\begin{array}{l}-0.155^{\star * *} \\
(0.0245)\end{array}$ \\
\hline 7.cb_pctl & $\begin{array}{c}-0.829^{* * *} \\
(0.0324)\end{array}$ & $\begin{array}{c}-0.531^{* * *} \\
(0.0233)\end{array}$ & $\begin{array}{c}-0.402^{* \star *} \\
(0.0351)\end{array}$ & $\begin{array}{c}-0.310^{* * *} \\
(0.0246)\end{array}$ & $\begin{array}{c}-0.793^{\star * *} \\
(0.0367)\end{array}$ & $\begin{array}{c}-1.001^{\star * *} \\
(0.0265)\end{array}$ & $\begin{array}{c}-0.472^{* \star *} \\
(0.0417)\end{array}$ & $\begin{array}{c}-0.437^{* * *} \\
(0.0287)\end{array}$ \\
\hline 8.cb_pctl & $\begin{array}{c}-1.460^{* * *} \\
(0.0391)\end{array}$ & $\begin{array}{l}-0.894^{* * *} \\
(0.0282)\end{array}$ & $\begin{array}{l}-0.703^{* * *} \\
(0.0375)\end{array}$ & $\begin{array}{c}-0.576^{* * *} \\
(0.0269)\end{array}$ & $\begin{array}{c}-1.403^{* * *} \\
(0.0473)\end{array}$ & $\begin{array}{c}-1.586^{* * *} \\
(0.0338)\end{array}$ & $\begin{array}{c}-0.838^{* * *} \\
(0.0511)\end{array}$ & $\begin{array}{c}-0.779^{* * *} \\
(0.0356)\end{array}$ \\
\hline 9.cb_pctl & $\begin{array}{l}-2.106^{* * *} \\
(0.0472)\end{array}$ & $\begin{array}{l}-1.294^{* * *} \\
(0.0353)\end{array}$ & $\begin{array}{l}-1.154^{* * *} \\
(0.0416)\end{array}$ & $\begin{array}{l}-1.016^{* * *} \\
(0.0311)\end{array}$ & $\begin{array}{l}-1.999^{* * *} \\
(0.0604)\end{array}$ & $\begin{array}{l}-2.243^{* * *} \\
(0.0437)\end{array}$ & $\begin{array}{l}-1.353^{* * *} \\
(0.0658)\end{array}$ & $\begin{array}{l}-1.226^{* * *} \\
(0.0465)\end{array}$ \\
\hline 10.cb_pctl & $\begin{array}{c}-3.376^{* * *} \\
(0.0692)\end{array}$ & $\begin{array}{c}-2.029 * * * \\
(0.0502)\end{array}$ & $\begin{array}{c}-2.200^{* * *} \\
(0.0590)\end{array}$ & $\begin{array}{c}-2.160^{\star * *} \\
(0.0442)\end{array}$ & $\begin{array}{c}-3.127^{\star * *} \\
(0.0895)\end{array}$ & $\begin{array}{c}-3.376^{\star * *} \\
(0.0644)\end{array}$ & $\begin{array}{c}-2.377^{* * *} \\
(0.0949)\end{array}$ & $\begin{array}{c}-2.079 * * * \\
(0.0681)\end{array}$ \\
\hline WAGE & $\begin{array}{c}-0.0134^{* * *} \\
(0.00252)\end{array}$ & $\begin{array}{c}0.231^{* * *} \\
(0.00201)\end{array}$ & $\begin{array}{l}-0.126^{* * *} \\
(0.00189)\end{array}$ & $\begin{array}{l}0.0806^{* * *} \\
(0.00147)\end{array}$ & & & & \\
\hline Observatio & 221,905 & 485,506 & 134,572 & 251,103 & 221,905 & 485,506 & 134,572 & 251,103 \\
\hline
\end{tabular}

Standard errors in parentheses

${ }^{* * *} p<0.01,{ }^{* *} p<0.05,{ }^{*} p<0.1$ 
Table 4. Effects of expected wage and Difficulty of Being Accepted, by Gender, on the First Choice

\begin{tabular}{|c|c|c|c|c|c|c|c|c|}
\hline \multirow[b]{4}{*}{ VARIABLE } & \multicolumn{2}{|c|}{$\begin{array}{l}\text { PANEL A } \\
\text { TECH }\end{array}$} & \multicolumn{2}{|c|}{$\begin{array}{l}\text { PANEL B } \\
\text { TAU }\end{array}$} & \multicolumn{2}{|c|}{$\begin{array}{c}\text { PANEL C } \\
\text { TECH }\end{array}$} & \multicolumn{2}{|c|}{$\begin{array}{l}\text { PANEL D } \\
\text { TAU }\end{array}$} \\
\hline & $\mathrm{F}$ & M & & M & $\mathrm{F}$ & & $\mathrm{F}$ & M \\
\hline & \multicolumn{4}{|c|}{ without controlling for major dummy variables } & \multicolumn{4}{|c|}{ controlling for major dummy variables } \\
\hline & $(1)$ & $(2)$ & $(3)$ & $(4)$ & $(5)$ & $(6)$ & $(7)$ & $(8)$ \\
\hline 1bn.cb_pct & $\begin{array}{c}-0.804^{* * *} \\
(0.0698)\end{array}$ & $\begin{array}{l}-2.205^{* * *} \\
(0.0510)\end{array}$ & $\begin{array}{l}-1.057^{* * *} \\
(0.0706)\end{array}$ & $\begin{array}{l}-0.911^{* * *} \\
(0.0516)\end{array}$ & $\begin{array}{c}-1.417^{* * *} \\
(0.106)\end{array}$ & $\begin{array}{l}-0.765^{\star * *} \\
(0.0730)\end{array}$ & $\begin{array}{c}-1.000^{* * *} \\
(0.119)\end{array}$ & $\begin{array}{c}-0.623^{* * *} \\
(0.0819)\end{array}$ \\
\hline \multirow[t]{2}{*}{ 2.cb_pctl } & $-0.470^{* * *}$ & $-1.223^{* * *}$ & $-0.745^{\star \star \star}$ & $-0.571^{* * *}$ & $-0.809^{* * *}$ & $-0.388^{* * *}$ & $-0.662^{* * *}$ & $-0.335^{\star * *}$ \\
\hline & $(0.0499)$ & $(0.0352)$ & $(0.0555)$ & $(0.0405)$ & $(0.0683)$ & $(0.0472)$ & $(0.0796)$ & $(0.0553)$ \\
\hline \multirow[t]{2}{*}{ 3.cb_pctl } & $-0.143^{* * *}$ & $-0.617^{* * *}$ & $-0.291^{* * *}$ & $-0.290^{* * *}$ & $-0.325^{\star * *}$ & $-0.0999^{* * *}$ & $-0.270^{* * *}$ & $-0.130^{* * *}$ \\
\hline & $(0.0419)$ & $(0.0292)$ & $(0.0473)$ & $(0.0350)$ & $(0.0499)$ & $(0.0350)$ & $(0.0595)$ & $(0.0415)$ \\
\hline \multirow[t]{2}{*}{ 4.cb_pctl } & $0.207^{* * *}$ & 0.0165 & $-0.128^{* * *}$ & $-0.146^{\star * *}$ & $0.128^{* * *}$ & $0.272^{* * *}$ & $-0.116^{* *}$ & $-0.0570^{*}$ \\
\hline & $(0.0364)$ & $(0.0255)$ & $(0.0447)$ & $(0.0320)$ & $(0.0389)$ & $(0.0275)$ & $(0.0491)$ & $(0.0340)$ \\
\hline \multirow[t]{2}{*}{ 6.cb_pctl } & $-0.565^{\star * *}$ & $-0.353^{* * *}$ & $-0.153^{* * *}$ & $-0.139^{* * *}$ & $-0.517^{\star * *}$ & $-0.594^{* * *}$ & $-0.157^{* * *}$ & $-0.213^{* * *}$ \\
\hline & $(0.0414)$ & $(0.0297)$ & $(0.0437)$ & $(0.0311)$ & $(0.0437)$ & $(0.0314)$ & $(0.0474)$ & $(0.0329)$ \\
\hline \multirow[t]{2}{*}{ 7.cb_pctl } & $-1.201^{* * *}$ & $-0.819^{\star * *}$ & $-0.570^{\star * *}$ & $-0.503^{\star * *}$ & $-1.115^{\star * \star}$ & $-1.311^{\star * *}$ & $-0.612^{\star \star \star}$ & $-0.670^{\star * *}$ \\
\hline & $(0.0495)$ & $(0.0361)$ & $(0.0476)$ & $(0.0342)$ & $(0.0555)$ & $(0.0404)$ & $(0.0568)$ & $(0.0396)$ \\
\hline \multirow[t]{2}{*}{ 8.cb_pctl } & $-1.887^{* * *}$ & $-1.301^{* * *}$ & $-0.889^{* * *}$ & $-0.773^{* * *}$ & $-1.766^{\star * *}$ & $-2.029^{* * *}$ & $-0.983^{* * *}$ & $-1.048^{* * *}$ \\
\hline & $(0.0607)$ & $(0.0460)$ & $(0.0513)$ & $(0.0379)$ & $(0.0720)$ & $(0.0535)$ & $(0.0694)$ & $(0.0492)$ \\
\hline \multirow[t]{2}{*}{ 9.cb_pctl } & $-2.829^{* * *}$ & $-1.742^{\star * *}$ & $-1.314^{\star * *}$ & $-1.168^{* * *}$ & $-2.625^{\star * *}$ & $-2.738^{* * *}$ & $-1.434^{* * *}$ & $-1.497^{* * *}$ \\
\hline & $(0.0812)$ & $(0.0590)$ & (0.0569) & $(0.0436)$ & $(0.0981)$ & $(0.0699)$ & (0.0888) & $(0.0639)$ \\
\hline \multirow[t]{2}{*}{ 10.cb_pctl } & $-4.141^{* * *}$ & $-2.600^{* * *}$ & $-2.354^{* * *}$ & $-2.210^{* * *}$ & $-3.673^{* * *}$ & $-4.032^{* * *}$ & $-2.420^{* * *}$ & $-2.275^{\star \star *}$ \\
\hline & $(0.117)$ & $(0.0876)$ & $(0.0810)$ & $(0.0595)$ & $(0.142)$ & $(0.105)$ & $(0.128)$ & $(0.0917)$ \\
\hline WAGE & $\begin{array}{c}-0.0139 * * * \\
(0.00340)\end{array}$ & $\begin{array}{c}0.239 * * * \\
(0.00287)\end{array}$ & $\begin{array}{l}-0.137^{* * *} \\
(0.00254)\end{array}$ & $\begin{array}{l}0.0785^{\star * *} \\
(0.00199)\end{array}$ & & & & \\
\hline Observatio & 221,905 & 485,506 & 134,572 & 251,103 & 221,905 & 485,506 & 134,572 & 251,103 \\
\hline
\end{tabular}

Standard errors in parentheses

${ }^{* * *} p<0.01,{ }^{* *} p<0.05,{ }^{*} p<0.1$ 
Table 5. Effects of expected wage and Difficulty of Being Accepted, by Gender, on the Second Choice

\begin{tabular}{|c|c|c|c|c|c|c|c|c|}
\hline \multirow[b]{4}{*}{ VARIABLE } & \multicolumn{2}{|c|}{$\begin{array}{l}\text { PANEL A } \\
\text { TECH }\end{array}$} & \multicolumn{2}{|c|}{$\begin{array}{l}\text { PANEL B } \\
\text { TAU }\end{array}$} & \multicolumn{2}{|c|}{$\begin{array}{c}\text { PANEL C } \\
\text { TECH }\end{array}$} & \multicolumn{2}{|c|}{$\begin{array}{c}\text { PANEL D } \\
\text { TAU }\end{array}$} \\
\hline & $\mathrm{F}$ & M & $\mathrm{F}$ & M & $\mathrm{F}$ & $\mathrm{M}$ & $\mathrm{F}$ & M \\
\hline & \multicolumn{4}{|c|}{ without controlling for major dummy variables } & \multicolumn{4}{|c|}{ controlling for major dummy variables } \\
\hline & $(1)$ & $(2)$ & $(3)$ & $(4)$ & $(5)$ & $(6)$ & $(7)$ & $(8)$ \\
\hline \multirow[t]{2}{*}{ 1bn.cb_pctl } & $-1.834^{* * *}$ & $-3.164^{* * *}$ & $-1.067^{* * *}$ & $-1.139^{* * *}$ & $-2.011^{* * *}$ & $-1.874^{* * *}$ & $-0.949 * * *$ & $-1.277^{* * *}$ \\
\hline & $(0.0801)$ & $(0.0562)$ & $(0.0819)$ & $(0.0566)$ & $(0.117)$ & $(0.0789)$ & $(0.133)$ & $(0.0923)$ \\
\hline \multirow[t]{2}{*}{ 2.cb_pctl } & $-1.187^{* * *}$ & $-1.908^{* * *}$ & $-0.653^{* * *}$ & $-0.801^{* * *}$ & $-1.296^{* * *}$ & $-1.197^{* * *}$ & $-0.552^{* * *}$ & $-0.851^{* * *}$ \\
\hline & $(0.0562)$ & $(0.0383)$ & $(0.0640)$ & $(0.0453)$ & $(0.0746)$ & $(0.0505)$ & $(0.0898)$ & $(0.0627)$ \\
\hline \multirow[t]{2}{*}{ 3.cb_pctl } & $-0.649^{* * *}$ & $-1.070^{* * *}$ & $-0.427^{* * *}$ & $-0.516^{\star * *}$ & $-0.700^{* * *}$ & $-0.618^{* * *}$ & $-0.372^{* * *}$ & $-0.528^{* * *}$ \\
\hline & $(0.0461)$ & $(0.0312)$ & $(0.0587)$ & $(0.0400)$ & $(0.0542)$ & $(0.0370)$ & $(0.0700)$ & $(0.0475)$ \\
\hline \multirow[t]{2}{*}{ 4.cb_pctl } & $-0.127^{\star \star *}$ & $-0.354^{\star * *}$ & $-0.182^{\star * *}$ & $-0.297^{\star \star *}$ & $-0.144^{* * *}$ & $-0.125^{\star * *}$ & $-0.155^{\star * *}$ & $-0.282^{\star * *}$ \\
\hline & $(0.0395)$ & $(0.0272)$ & $(0.0548)$ & $(0.0370)$ & $(0.0418)$ & $(0.0292)$ & $(0.0583)$ & $(0.0395)$ \\
\hline \multirow[t]{2}{*}{ 6.cb_pctl } & $-0.262^{* * *}$ & $-0.0473^{*}$ & $-0.0907^{*}$ & $-0.0620^{*}$ & $-0.269^{* * *}$ & $-0.276^{* * *}$ & $-0.130^{\star *}$ & $-0.0895^{* *}$ \\
\hline & $(0.0403)$ & $(0.0274)$ & $(0.0524)$ & $(0.0349)$ & $(0.0424)$ & $(0.0292)$ & $(0.0555)$ & $(0.0374)$ \\
\hline \multirow[t]{2}{*}{ 7.cb_pctl } & $-0.511^{* * *}$ & $-0.311^{* * *}$ & $-0.197^{* * *}$ & $-0.106^{\star * *}$ & $-0.532^{\star * *}$ & $-0.764^{* * *}$ & $-0.296^{* * *}$ & $-0.175^{\star * *}$ \\
\hline & $(0.0437)$ & $(0.0309)$ & $(0.0528)$ & $(0.0357)$ & $(0.0503)$ & $(0.0358)$ & $(0.0624)$ & $(0.0425)$ \\
\hline \multirow[t]{2}{*}{ 8.cb_pctl } & $-1.097^{* * *}$ & $-0.608^{* * *}$ & $-0.487^{* * *}$ & $-0.375^{\star * *}$ & $-1.120^{* * *}$ & $-1.273^{* * *}$ & $-0.665^{\star * *}$ & $-0.475^{\star * *}$ \\
\hline & $(0.0519)$ & $(0.0364)$ & $(0.0559)$ & $(0.0387)$ & $(0.0646)$ & $(0.0451)$ & $(0.0765)$ & $(0.0527)$ \\
\hline \multirow[t]{2}{*}{ 9.cb_pctl } & $-1.575^{\star \star *}$ & $-0.993^{* * *}$ & $-0.969^{* * *}$ & $-0.864^{* * *}$ & $-1.588^{* * *}$ & $-1.900^{* * *}$ & $-1.241^{* * *}$ & $-0.908^{* * *}$ \\
\hline & $(0.0602)$ & $(0.0449)$ & $(0.0621)$ & $(0.0447)$ & $(0.0811)$ & $(0.0581)$ & $(0.0991)$ & $(0.0690)$ \\
\hline \multirow[t]{2}{*}{ 10.cb_pctl } & $-2.795^{\star * *}$ & $-1.670^{* * *}$ & $-2.031^{* * *}$ & $-2.129^{\star * *}$ & $-2.753^{\star * *}$ & $-2.933^{* * *}$ & $-2.310^{\star * *}$ & $-1.825^{* * *}$ \\
\hline & $(0.0877)$ & $(0.0626)$ & $(0.0869)$ & $(0.0663)$ & $(0.120)$ & $(0.0846)$ & $(0.142)$ & $(0.102)$ \\
\hline WAGE & $\begin{array}{c}-0.0146^{* * *} \\
(0.00376)\end{array}$ & $\begin{array}{c}0.221^{* * *} \\
(0.00283)\end{array}$ & $\begin{array}{l}-0.112^{* * *} \\
(0.00287)\end{array}$ & $\begin{array}{l}0.0834^{* * *} \\
(0.00219)\end{array}$ & & & & \\
\hline Observation & 213,576 & 467,262 & 104,078 & 215,642 & 213,576 & 467,262 & 104,078 & 215,642 \\
\hline
\end{tabular}


Table 6. Effects of expected wage and Difficulty of Being Accepted, by Gender, on Considered Choice Set controlling for major dummy variables

\begin{tabular}{|c|c|c|c|c|c|c|c|c|}
\hline \multirow[b]{4}{*}{ VARIABLES } & \multicolumn{4}{|c|}{ TECH } & \multicolumn{4}{|c|}{ TAU } \\
\hline & \multicolumn{2}{|c|}{$\begin{array}{c}\text { Considered Choice Set } \\
\text { PANEL A }\end{array}$} & \multicolumn{2}{|c|}{$\begin{array}{c}\text { First Choice, Given } \\
\text { the Considered } \\
\text { Choice Set } \\
\text { PANEL B }\end{array}$} & \multicolumn{2}{|c|}{$\begin{array}{c}\text { Considered Choice Set } \\
\text { PANEL A }\end{array}$} & \multicolumn{2}{|c|}{$\begin{array}{c}\text { First Choice, Given } \\
\text { the Considered } \\
\text { Choice Set } \\
\text { PANEL B }\end{array}$} \\
\hline & $\mathrm{F}$ & $\mathrm{M}$ & F & $\mathrm{M}$ & $\mathrm{F}$ & $\mathrm{M}$ & $\mathrm{F}$ & $\mathrm{M}$ \\
\hline & $(1)$ & $(2)$ & (3) & $(4)$ & (5) & (6) & (7) & (8) \\
\hline \multirow[t]{2}{*}{ 1bn.cb_pctl } & $-1.503^{* * *}$ & $-1.158^{* * *}$ & $0.709^{* * *}$ & $1.181^{* * *}$ & $-0.723^{* * *}$ & $-0.541^{* * *}$ & $0.583^{* * *}$ & $1.053^{* * *}$ \\
\hline & $(0.0797)$ & $(0.0550)$ & $(0.179)$ & $(0.122)$ & $(0.0832)$ & $(0.0579)$ & $(0.190)$ & $(0.131)$ \\
\hline \multirow[t]{2}{*}{ 2.cb_pctl } & $-0.935^{\star * *}$ & $-0.703^{* * *}$ & $0.601^{* * *}$ & $0.856^{* * *}$ & $-0.467^{* * *}$ & $-0.346^{* * *}$ & $0.303^{* *}$ & $0.811^{* * *}$ \\
\hline & $(0.0514)$ & $(0.0357)$ & $(0.115)$ & $(0.0787)$ & $(0.0580)$ & $(0.0404)$ & $(0.130)$ & $(0.0894)$ \\
\hline \multirow[t]{2}{*}{ 3.cb_pctl } & $-0.450^{* * *}$ & $-0.314^{* * *}$ & $0.430^{* * *}$ & $0.484^{* * *}$ & $-0.226^{\star * *}$ & $-0.190^{* * *}$ & $0.372^{* * *}$ & $0.573^{* * *}$ \\
\hline & $(0.0379)$ & $(0.0267)$ & $(0.0808)$ & $(0.0544)$ & $(0.0457)$ & $(0.0318)$ & $(0.0983)$ & $(0.0667)$ \\
\hline \multirow[t]{2}{*}{ 4.cb_pctl } & 0.0271 & $0.103^{* * *}$ & $0.316^{* * *}$ & $0.383^{* * *}$ & $-0.0948^{* *}$ & $-0.110^{* * *}$ & $0.151^{*}$ & $0.298^{* * *}$ \\
\hline & $(0.0297)$ & $(0.0214)$ & $(0.0595)$ & $(0.0399)$ & $(0.0394)$ & $(0.0273)$ & $(0.0792)$ & $(0.0533)$ \\
\hline \multirow[t]{2}{*}{ 6.cb_pctl } & $-0.427^{* * *}$ & $-0.457^{* * *}$ & $-0.309^{* * *}$ & $-0.391^{* * *}$ & $-0.195^{\star * *}$ & $-0.225^{* * *}$ & $-0.223^{* * *}$ & $-0.214^{* * *}$ \\
\hline & $(0.0317)$ & $(0.0228)$ & $(0.0644)$ & $(0.0437)$ & $(0.0382)$ & $(0.0264)$ & $(0.0747)$ & $(0.0503)$ \\
\hline \multirow[t]{2}{*}{ 7.cb_pctl } & $-0.863^{* * *}$ & $-1.086^{* * *}$ & $-0.736^{\star * *}$ & $-0.698^{* * *}$ & $-0.578^{* * *}$ & $-0.573^{\star * *}$ & $-0.666^{\star * *}$ & $-0.704^{* * *}$ \\
\hline & $(0.0382)$ & $(0.0280)$ & $(0.0824)$ & $(0.0579)$ & $(0.0433)$ & $(0.0299)$ & $(0.0889)$ & $(0.0601)$ \\
\hline \multirow[t]{2}{*}{ 8.cb_pctl } & $-1.521^{* * *}$ & $-1.726^{\star * *}$ & $-0.923^{* * *}$ & $-0.950^{* * *}$ & $-1.047^{* * *}$ & $-1.018^{* * *}$ & $-0.958^{* * *}$ & $-0.923^{* * *}$ \\
\hline & $(0.0488)$ & $(0.0353)$ & $(0.111)$ & $(0.0767)$ & $(0.0513)$ & $(0.0356)$ & $(0.110)$ & $(0.0751)$ \\
\hline \multirow[t]{2}{*}{ 9.cb_pctl } & $-2.167^{* * *}$ & $-2.450 * * *$ & $-1.392^{* * *}$ & $-1.031^{* * *}$ & $-1.686^{\star * *}$ & $-1.610^{* * *}$ & $-1.111^{* * *}$ & $-1.155^{* * *}$ \\
\hline & $(0.0622)$ & $(0.0454)$ & $(0.149)$ & $(0.104)$ & $(0.0641)$ & $(0.0451)$ & $(0.143)$ & $(0.100)$ \\
\hline \multirow[t]{2}{*}{ 10.cb_pctl } & $-3.394^{* * *}$ & $-3.673^{* * *}$ & $-1.477^{\star \star *}$ & $-1.193^{* \star *}$ & $-2.871^{* * *}$ & $-2.671^{* * *}$ & $-1.481^{\star \star *}$ & $-1.277^{* \star *}$ \\
\hline & $(0.0921)$ & $(0.0666)$ & $(0.220)$ & $(0.154)$ & $(0.0918)$ & $(0.0653)$ & $(0.202)$ & $(0.144)$ \\
\hline Observations & 221,905 & 485,506 & 16,658 & 36,488 & 134,572 & 251,103 & 12,358 & 26,095 \\
\hline
\end{tabular}

Note: Majors

Standard errors in parentheses

${ }^{* * *} p<0.01,{ }^{* *} p<0.05,{ }^{*} p<0.1$ 
Table 7. Measures of the Impact of Gender Composition in the Major on the Pattern of Applications

\begin{tabular}{|c|c|c|c|}
\hline & \multicolumn{3}{|c|}{ TECH } \\
\hline & Index of Dissimilarity & \multicolumn{2}{|c|}{$\begin{array}{c}\text { Percent Female in Major } \\
\text { coef. }\end{array}$} \\
\hline Unidimensional Preference Model & 0.414 & 0.0203 & $(.00049)$ \\
\hline First Choice of All Alternatives & 0.434 & 0.026 & $(.00075)$ \\
\hline Second Choice of Remaining Alternatives & 0.367 & 0.016 & $(.00067)$ \\
\hline Considered Options Model & 0.425 & 0.0206 & $(.0005)$ \\
\hline First Choice, Conditional on Considered Op & & 0.0094 & $(.0013)$ \\
\hline
\end{tabular}

TAU

Index of Dissimilarity Percent Female in Major

\begin{tabular}{lrrr} 
& & coef. & se \\
\hline Unidimensional Preference Model & 0.466 & 0.011 & $(.00066)$ \\
First Choice of All Alternatives & 0.482 & 0.013 & $(.00090)$ \\
Second Choice of Remaining Alternatives & 0.404 & 0.0081 & $(.00099)$ \\
Considered Options Model & 0.492 & 0.012 & $(.00069)$ \\
& & & \\
First Choice, Conditional on Considered Options & & 0.0038 & $(.0019)$ \\
\hline
\end{tabular}

Note: The coefficient for percent female in major is from the model estimated on female applicants only 


\section{Appendix B. Tests for the Validity of the Unidimensional Preferences Model}

\begin{tabular}{|c|c|c|c|}
\hline \multicolumn{4}{|l|}{ Men and Women Combined } \\
\hline & Model & & \\
\hline Expected Wage & $\mathrm{x}$ & $x$ & \\
\hline Lagged Sex-Composition of Major & & $x$ & \\
\hline Risk Score for Person-Potential Major Match & $x$ & $x$ & $x$ \\
\hline Dummy Variables for Majors & & & $x$ \\
\hline Hausman test $(\mathrm{TECH}) \mathrm{p}$-value & $<.00001$ & $<.00001$ & $<.00001$ \\
\hline Hausman test (TAU) pvalue & $<.00001$ & $<.00001$ & $<.00001$ \\
\hline \multicolumn{4}{|l|}{ Women Only } \\
\hline & Model & & \\
\hline Expected Wage & $x$ & $x$ & \\
\hline Lagged Sex-Composition of Major & & $x$ & \\
\hline Risk Score for Person-Potential Major Match & $x$ & $x$ & $x$ \\
\hline Dummy Variables for Majors & & & $x$ \\
\hline Hausman test (TECH) p-value & $<.00001$ & $<.00001$ & $<.00001$ \\
\hline Hausman test (TAU) pvalue & $<.00001$ & $<.00001$ & $<.00001$ \\
\hline \multicolumn{4}{|l|}{ Men Only } \\
\hline & Model & & \\
\hline Expected Wage & $\mathrm{x}$ & $x$ & \\
\hline Lagged Sex-Composition of Major & & $x$ & \\
\hline Risk Score for Person-Potential Major Match & $x$ & $x$ & $x$ \\
\hline Dummy Variables for Majors & & & $x$ \\
\hline Hausman test (TECH) p-value & $<.00001$ & $<.00001$ & $<.00001$ \\
\hline Hausman test (TAU) pvalue & $<.00001$ & $<.00001$ & $<.00001$ \\
\hline
\end{tabular}

